\title{
Integración de las TIC en la Unidad Educativa Particular Terranova. Resultados de la primera fase de investigación
}

\section{Integration df ICT in the Particular Educational School Terranova. The Results of the First Research Phase}

\author{
Antonio Francisco Martin García \\ Máster interuniversitario de Tecnología Educativa: E-Learning y \\ Gestión del Conocimiento \\ antoniomg85@hotmail.com
}

Recibido: 16 de marzo de 2016; aceptado: 21 de Mayo de 2016

\section{Cómo citar este artículo}

Martin, A.F. (2016). Integración de las Tic en la Unidad Educativa Particular Terranova. Resultados de la primera fase de investigación. Espiral, Revista de Docencia e Investigación, 6(1), 107 - 136

\section{Resumen}

Objetivo. El presente artículo de investigación tiene como propósito diagnosticar el estado de integración de las TIC en los procesos de enseñanza-aprendizaje, y enfatiza en el estado de integración de las nuevas tecnologías de la información y la comunicación (TIC) en la Unidad Educativa Particular Terranova, situada en Quito, Ecuador. El marco teórico está centrado en las TIC en la enseñanza, sus posibilidades y obstáculos, algunas experiencias de integración, y las últimas tendencias, desafíos y progresos; y en la competencia digital, tanto del docente como del alumnado.

Metodología. Se utiliza parte de un paradigma interpretativo y se encauza hacia una investigación de tipo empírica exploratoria, cuya metodología es mixta y en la que el enfoque tanto cuantitativo como cualitativo tiene un gran peso durante el proceso de investigación.

Resultados y conclusiones. Se exponen los resultados obtenidos en la primera fase de investigación, concretamente del cuestionario y de la revisión documental. Los cuales evidenciaron la existencia de cierto nivel de integración de las TIC en los procesos de enseñanzaaprendizaje, al mismo tiempo que se señaló la necesidad institucional de proveer a un número considerable de sus docentes con más formación o incluso con un programa integral de capacitación en TIC.

Palabras clave:

Integración de las TIC, formación en TIC, las TIC en la enseñanza, competencia digital, tendencias en TIC.

\begin{abstract}
This research paper aims to diagnose the state of integration of ICT in the teaching and learning processes and focuses on the state of integration of new information and communications technology (ICT) in the Special Education Unit Terranova located in Quito, Ecuador. The theoretical framework focuses on ICT in education, its possibilities and obstacles, some integration experiences and the latest trends, challenges and progress; and of digital competence of both teachers and students.

A part of an interpretive paradigm is used and it focuses towards an exploratory empirical research whose methodology is mixed and in which both quantitative and qualitative approach has great weight during the investigation process.

The results obtained in the first phase of research are presented especially, the questionnaire and documentary review. They showed the existence of a certain level of integration of ICT in the teaching and learning process while an institutional need to provide a considerable number of teachers with more training or even an integral training program in ICT was noted.
\end{abstract}

\section{Keywords}

Integration of ICT, ICT training, ICT in education, digital literacy, ICT trends. 


\section{Introducción}

Esta investigación preliminar versa sobre el estado de integración de las nuevas tecnologías de la información y la comunicación (TIC) en la Unidad Educativa Particular Terranova, situada en Quito, Ecuador. Esta propuesta nace fruto de la motivación personal del investigador, debido a que trabaja como coordinador de TIC en el centro objeto de estudio, y por otro lado, al interés del centro por integrar las TIC en los procesos de enseñanza-aprendizaje.

El contexto se sitúa en un centro educativo privado que oferta educación preescolar, primaria, secundaria y bachillerato. Su plantilla está formada por un total de 119 docentes y en el curso académico 2015/2016 estaban matriculados 1514 alumnos.

El organigrama del centro consiste en un rector, encargado de liderar y dirigir, por un lado, a los tres directores de sección, y por otro lado, a la directora académica, quien a su vez está encargada de dirigir a las coordinadoras académicas de cada sección.

El centro que se encuentra inmerso en un proceso de modernización tecnológica desde enero del 2013. Cuenta con conexión a internet, infraestructura de red para conexiones alámbricas e inalámbricas, y una intranet para el personal. Las secciones de preescolar y primaria disponen de sendas salas de profesores con ordenadores conectados a internet. También se dispone de un aula mediateca en secundaria con 25 ordenadores de sobremesa y un aula de investigación con 8 ordenadores en la biblioteca de la sección primaria.

En agosto de 2015 se compraron computadoras portátiles para docentes, así como se instalaron infocus y parlantes en todas las aulas de la Institución. En agosto de 2015 se contaba con 11 pizarras digitales Mimio Board, una de ellas para la sección de secundaria, y 51 tabletas iPads para los cursos de segundo y tercero de educación primaria. También se realizó la apuesta de contratar en ese mismo mes, por primera vez, a un coordinador de tecnología educativa. El centro también cuenta con la ayuda de un equipo de sistemas informáticos.

El objetivo general de esta investigación es el de diagnosticar el estado de integración de las TIC en los procesos de enseñanza-aprendizaje del centro. Para la consecución de tal propósito se definen sus objetivos específicos: determinar en qué dimensiones se va a focalizar el diagnóstico del estado de integración de las TIC, y determinar qué técnicas e instrumentos cuantitativos y cualitativos concretos serán utilizados para realizar el diagnóstico.

\section{Estado del arte}

\section{Las TIC en la enseñanza}

Las TIC son parte indiscutible de nuestro día a día y están inmersas en todos los aspectos de nuestras vidas desde hace algunos años, conformando así la realidad de nuestro presente y futuro (Hernández, 2012). En la actualidad es frecuente identificar a las TIC no solo como herramientas de acceso al conocimiento sino también como herramientas que favorecen los procesos de enseñanza-aprendizaje. Poole (1999) afirmaba en la década de los noventa que los sistemas informáticos facilitan el acceso de los alumnos al conocimiento, pero también pueden ser de utilidad para los docentes. Es desde ese enfoque que las TIC comienzan a considerarse herramientas para la enseñanza.

Aunque en un comienzo se percibió la llegada de las TIC a la enseñanza con mucho optimismo e ilusión, tras veinte años de estudios se ha llegado a la conclusión de que el conocimiento y la posibilidad del uso de estas tecnologías pertenecen al conjunto de competencias que demanda la sociedad actual, pero sin implicar obligatoriamente una mejora en el aprendizaje significativo (Sanmamed, 2005).

Por su parte y centrándonos en el contexto del centro de estudio en este trabajo, Lugo (2010) sostiene que: 
en el marco de un escenario de desigualdad y heterogeneidad, América Latina se enfrenta a la certeza de que, a pesar que las TIC llegaron para quedarse, no hay evidencia empírica de que su integración en las escuelas promueva mejores logros de aprendizajes (p. 53).

Por otro lado, se debe prestar atención a los cambios que precisa la integración de las TIC en la enseñanza. Las infraestructuras de los centros educativos necesitan adaptarse y modernizarse para lograr una integración exitosa, pero también docentes y estudiantes deben afrontar cambios (Vera, Torres y Martínez, 2014). La función docente se transforma hacia un nuevo enfoque en el que su tarea se dirige a fomentar que los estudiantes busquen y descubran el conocimiento, como tradicionalmente se ha realizado, ser un agente puramente transmisor de conocimiento a estudiantes considerados como agentes pasivos (De Juanas y Fernández, 2008). Otros autores afirman que "el profesorado debe aprender a afrontar nuevos retos y problemas educativos que no existían hace pocos años, como el saber integrar y usar pedagógicamente las tecnologías de la información y comunicación" (Villatoro, 2011, citado por Hernández, 2012, p. 64).

\section{Posibilidades y obstáculos}

Empleando las palabras de Chacón (2009): "el mayor potencial de las Nuevas Tecnologías de la Información y la Comunicación (NTIC) viene derivado de las capacidades de manipulación, almacenamiento y distribución de la información de una manera fácil, rápida y accesible para todas las personas" (p. 1). Estas capacidades son realmente interesante desde el campo de la educación, pues pueden jugar un papel altamente potenciador en los procesos de enseñanza-aprendizaje.

A pesar de ello, Cutanda (2002) nos dice que no se pueden ignorar algunas de sus problemáticas, entre las que destaca que la velocidad con la que se producen y renuevan las TIC contrasta en muchos casos con el inmovilismo en el que tienden a desenvolverse muchas de las instituciones educativas, tanto formales como informales o no formales.

También se debe tener en consideración que las TIC no son un instrumento homogéneo, algunos usos pueden ser más beneficiosos para algunas asignaturas u otras, por ejemplo, el uso de software de simulaciones y modelos ha demostrado ser más efectivo para el aprendizaje de ciencias y matemáticas, mientras que el uso del procesador de textos y software de comunicación ha probado ser de ayuda para el desarrollo del lenguaje y destrezas de comunicación de los estudiantes (Claro, 2010).

Desde la posición de Cabero (2001, pp. 16-72), las tecnologías por sí mismas no resuelven los problemas educativos, pues se tratan de medios cuya eficacia depende de su potencialidad tecnológica para transmitir, manipular e interaccionar información por un lado, y de las relaciones que se establezcan con otros elementos curriculares, como el papel del profesor y el estudiante en el proceso formativo. Salinas (2000) sostiene que "el énfasis se debe poner en la docencia, en los cambios de estrategias didácticas de los profesores, en los sistemas de comunicación y distribución de materiales de aprendizaje, en lugar de enfatizar la disponibilidad y las potencialidades de las tecnologías" (p. 54).

El mismo autor Cabero (2010, p. 43) define una serie de posibilidades por las cuales las TIC son de apoyo para la enseñanza:

- Ampliación de la oferta informativa.

- Creación de entornos flexibles para el aprendizaje.

- Eliminación de las barreras espacio-temporales.

- Incremento de las modalidades comunicativas.

- Potenciación de los escenarios y entornos interactivos. 
- Favorecer el aprendizaje independiente y autoaprendizaje.

- Nuevas posibilidades para la orientación y tutorización y facilitar formación permanente, entre otros.

Bosco (2005, p. 25) sostiene que la limitación principal que presentan las TIC en los procesos de enseñanza-aprendizaje es la falsa creencia de que su mero uso puede cambiar positivamente la docencia. El mismo autor sugiere algunas medidas que la podrían contrarrestar:

- Apoyo continuo a todas las iniciativas de mejora de la enseñanza incorporando las TIC por parte de las instituciones educativas.

- Suministro de recursos para el desarrollo de materiales digitales adaptados a las posibilidades del multimedia interactivo ya que pueden suponer una mejora en los procesos de comprensión.

- Incentivos para la formación de docentes en elaboración de materiales interactivos y nuevas metodologías apoyadas en las TIC.

El estudio de la British Educational Communications and Technology Agency (BECTA, 2004 , p. 20) fue uno de los más importantes a nivel internacional, puesto que revisó los estudios realizados sobre las limitaciones para la integración de las TIC en la enseñanza; en el que se señalan dos tipos de obstáculos, los relativos al profesor y los relacionados con las institucio- nes. En la tabla 1 se muestran los principales hallazgos.

Años más tarde se pudo encontrar el estudio que realizaron Casas, Barrantes y Luengo (2011) sobre los obstáculos percibidos por los docentes para la integración de las TIC, a partir de un análisis factorial de una muestra de 567 profesores que trabajaban en 418 centros de educación infantil y primaria en Extremadura, España. Como resultado se encontró que el mayor obstáculo era la falta de formación en competencia digital docente, que incluso en muchos casos era considerada inferior a la de los estudiantes. La falta de modelos de integración de las TIC y de tiempo para formarse en el centro dentro de su horario laboral fue otra importante limitación para que los profesores desarrollasen su competencia digital. Por último, el tercer mayor obstáculo encontrado fue la falta de ordenadores de fácil acceso para docentes dentro y fuera de las aulas.

A juicio de Ruiz y Sánchez (2014), el uso de las TIC en el aula es cada vez más una realidad en muchos países, sus posibilidades y potencialidades en relación con su aplicación en contextos educativos siguen siendo en la actualidad un tema pendiente de investigar con un mayor grado de profundidad. Ambos autores también coinciden en que "existe una amplia literatura que señala la valoración positiva que el alumnado hace de los distintos recursos tecnológicos puestos al servicio del proceso de enseñanza-aprendizaje" (p. 180).

Tabla 1. Limitaciones para la integración de las TIC

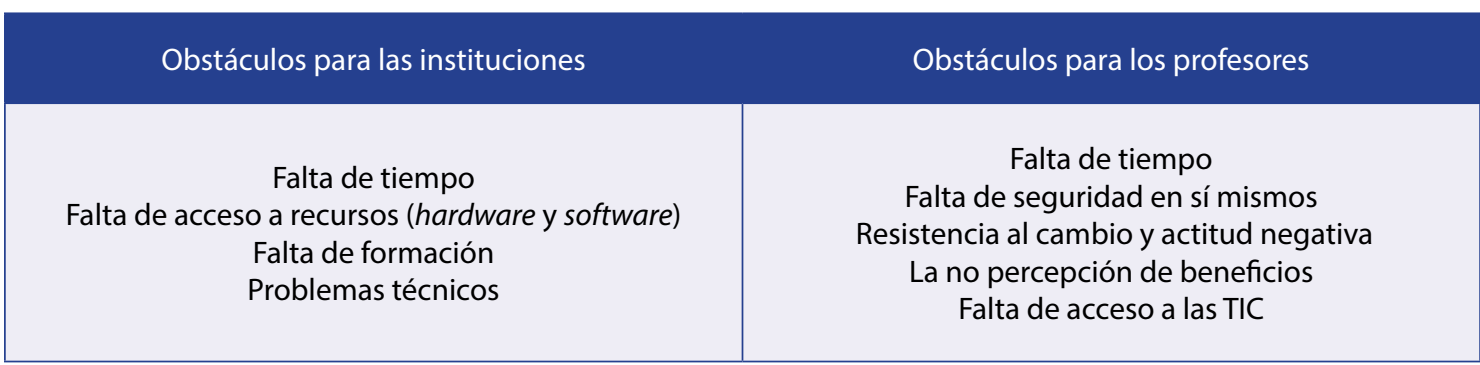




\section{Experiencias de integración}

A finales de la década de los 90 ya se podían encontrar estudios sobre la integración de las TIC en la enseñanza. Un estudio destacado fue llevado a cabo por Wenglinsky (1998), en el mismo se analizaron diferentes usos de las TIC en las escuelas, especialmente en lo que se refiere al uso de ordenadores y a los resultados en matemáticas obtenidos en la prueba "National Assessment of Educational Progress" (NAEP) en Estados Unidos. El estudio demostró que la tecnología podía hacer una diferencia dependiendo de cómo era usada, es decir, cuando los computadores eran usados para desarrollar algunas tareas, como aplicar habilidades de análisis, evaluación y síntesis, y cuando los profesores estaban preparados para dirigir a los estudiantes hacia usos más productivos, las TIC sí parecían estar asociadas con mejoras significativas en el logro en matemáticas.

Años más tarde se siguieron realizando investigaciones entre las que se encuentra el "ImpaCT2". Este fue un estudio en profundidad llevado a cabo por Harrison, Comber, Fisher, Haw, Lewin, Lunzer y Watling (2002) en 60 escuelas destacadas en el uso de las TIC. En este se encontró que el uso del procesador de texto aceleraba y reforzaba el desarrollo de la escritura en educación primaria. Otros estudios han demostrado que la naturaleza visual de algunas tecnologías, particularmente animaciones, simulaciones e imaginería móvil involucra más a los estudiantes y refuerza la comprensión de conceptos (Passey y Rogers, 2004; HMIE, 2005; citados en Condie y Munro, 2007).

Font, Hernández, Ochoa y Hernández (2007) trabajaron en el estudio y el análisis que el impacto tecnológico del Diseño Asistido y del empleo de las TIC habían supuesto en la docencia de la Ingeniería Gráfica. El estudio se centró en tres aspectos: el ámbito docente, el ámbito de la innovación y el ámbito de investigación. Las conclusiones más destacables del estudio según palabras de los propios autores del estudio fueron las siguientes:
- Los docentes habían incorporado la Enseñanza Asistida por Ordenador, la utilización de Aplicaciones Didácticas Interactivas (ADI) y el uso de las TIC a su metodología.

- El empleo de las ADI en la Enseñanza Asistida por Ordenador reducía el tiempo requerido para la exposición teórica; mejoraba la visualización de los modelos, de los enunciados y de las soluciones posibles y aumentaba el interés y la comprensión del alumnado.

- $\quad$ El Diseño Asistido por ordenador 3D y las TIC aportaban nuevas herramientas de modelado, construcción, visualización y localización de la información, que han favorecido la docencia y el aprendizaje.

- Se constató una creciente incorporación de la Enseñanza Asistida por Ordenador, así como de la realización y empleo de Aplicaciones Didácticas Interactivas y creación de páginas WEB con la finalidad de disponer de mejores medios para exponer y facilitar el estudio de los contenidos.

- Se observó la importancia, que cada vez más, se está dando a la innovación didáctica como vehículo para la mejora de la Calidad Docente (pp. 7-8).

Pantoja y Huertas (2010) realizaron una investigación sobre la integración de las TIC por parte del profesorado de tecnología de los centros TIC de Educación Secundaria de la provincia de Jaén, España. Se analizó el papel que estos docentes le daban a las TIC en la enseñanza, la formación en TIC que poseían y la importancia que le atribuían. También se indagó en los usos y las principales dificultades que afrontaban cuando las intentaban integrar en su tarea docente.

En los resultados se encontró que la mayoría de profesores consideraba que las TIC ayudaban a sus alumnos a mejor la adquisición de conocimientos y acceso a la información, al mismo tiempo que les permitía a ellos acceder a una gran cantidad de documentación para pre- 
parar sus clases, elaborar materiales educativos propios, complementar al libro de texto, y encontrar recursos educativos y programas útiles para sus prácticas docentes. También se encontraron debilidades en el estudio. Los docentes calificaron su formación en TIC de insuficiente y reconocieron que lo que aprendieron fue por sí mismos. También calificaron de laboriosa tanto la preparación de materiales informáticos para el aula como la adecuación del software a los contenidos, pues en su opinión los materiales didácticos disponibles en internet no se adaptaban a las necesidades reales del aula por lo que reclamaban más y mejores. Por último, se reflejó una falta de interés y motivación en buena parte de los docentes.

En el curso académico 2012/13 se llevó a cabo un proyecto interdisciplinario y colaborativo por parte de un grupo de maestros y profesores de tecnología, música y religión del Instituto Público Cañiza en Galicia, España. Además contó con el asesoramiento del Centro de Formación y Recursos Vigo. El proyecto se basaba en una metodología activa con participación bidireccional entre profesores y estudiantes, principalmente, pero también con familiares de los estudiantes. Los resultados fueron positivos en cuanto que se estableció un espacio virtual permanente para el trabajo colaborativo de docentes, los mismos que mejoraron su básica competencia digital inicial y la frecuencia de utilización de las TIC en el aula (Fernández, 2014).

Álvarez (2012) detalla dos experiencias de integración de las TIC para mejorar las habilidades de lectura y escritura de estudiantes preuniversitarios a través de entornos virtuales de aprendizaje. La primera experiencia consistió en un curso de seis módulos sobre habilidades de reformulación en la plataforma Moodle, en la que los estudiantes presentaron una disminución en su participación en el curso por el exceso de actividades, al mismo tiempo que indicaron que les hubiera gustado que tanto sus compañeros como ellos mismos hubiesen participado más activamente en las actividades grupales. En la segunda experiencia, se realizó un taller de lectoescritura dentro la plataforma Facebook combinado con un blog que hacía de repositorio de los materiales teóricos digitales sobre los temas y contenidos.

A pesar de que la plataforma o red social Facebook era un espacio interesante para la reunión virtual de los docentes con los estudiantes, este espacio por sí solo no sirvió para que se produjese una mejora en las habilidades tanto de lectura como de escritura.

Otra experiencia educativa de integración de las TIC, en concreto un curso en la plataforma Moodle, con la finalidad de mejorar el desarrollo de las competencias de lectura y escritura a nivel universitario y dentro de un currículo abierto y flexible fue el que estudiaron Morán y Álvarez (2014). El estudio de caso se realizó en la Universidad Nacional de General Sarmiento, Argentina, en dos fases bien definidas. En la primera se recogieron datos sobre el diseño y la implementación de la experiencia directa del observador-participante, entrevistas a profesores y un cuestionario al alumnado. En la segunda se analizaron los datos obtenidos, prestando atención al diseño propuesto, su implementación y los resultados centrados en aspectos curriculares, actividades, materiales y estrategias didácticas y participación estudiantil.

En el estudio se encontró que un gran número de alumnos no participaron en el curso debido a que presentaron dificultades con el uso y el acceso a la plataforma Moodle. Ello incidió en una necesidad de alfabetizar a los alumnos en el uso de las TIC con fines educativos. Aquellos alumnos que sí pudieron acceder al curso y leer los materiales directamente desde la pantalla calificaron positivamente $y$ de gran utilidad el curso. Los docentes, por su parte, destacaron las siguientes fortalezas de la experiencia: 


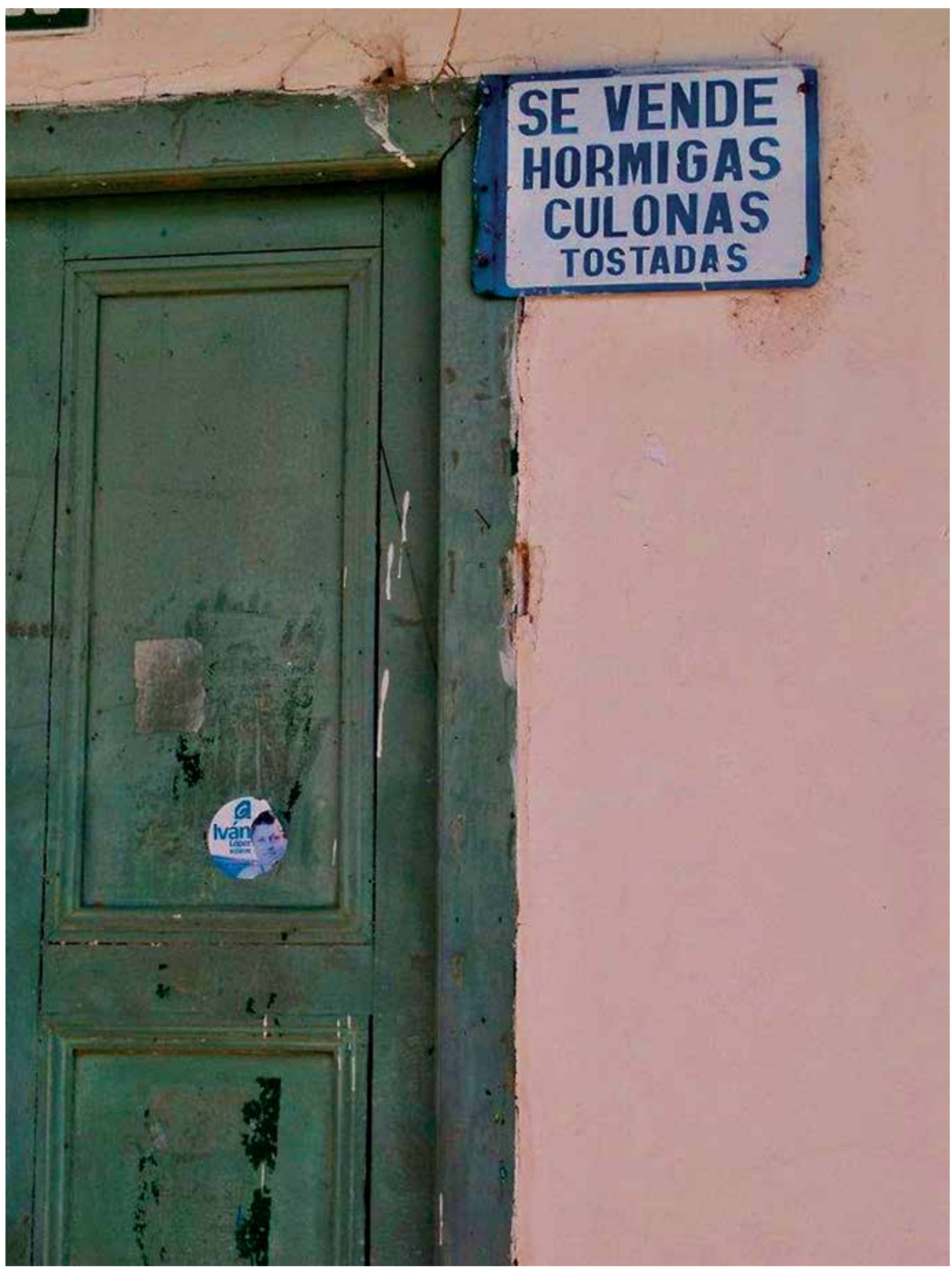


- Se creó una estrecha relación entre las clases presenciales y las virtuales.

- Continuidad a la frecuencia y ritmo de trabajo, ya que solía verse interrumpido entre una clase y otra.

- Facilidad en la identificación de las dificultades de la lectura y la escritura del alumnado gracias al registro de la plataforma Moodle.

También se han llevado a cabo recientemente experiencias de formación docente para el uso didáctico de las TIC. Sánchez (2015) presentó una propuesta de formación de profesores universitarios en la integración de las TIC en la enseñanza, a partir de la implementación del Seminario "Innovación de la práctica docente con apoyo de TIC para Trabajo Social", basado en los modelos Substitution Augmentation Modification Redefinition (SAMR) ${ }^{1}$ y Technological Pedagogical Content Knowledge (TPCK) ${ }^{2}$. El seminario, de seis meses de duración, se impartió al profesorado de la Escuela Nacional de Trabajo Social, que pertenece a la Universidad Nacional Autónoma de México y tuvo un enfoque constructivista y de trabajo colaborativo centrado en la planeación didáctica, la práctica docente, la innovación educativa y el uso didáctico de las TIC.

El Seminario se basó en la investigación, análisis, discusión, realimentación, interacción, comunicación permanente y construcción colaborativa de propuestas enfocadas hacia la innovación educativa a través de la integración de las TIC en la enseñanza. La experiencia supuso un excelente espacio para la discusión, análisis y aplicación de diferentes herramientas tecnológicas con fines didácticos y adaptados a las necesidades de cada profesor. Se halló una vinculación de la teoría con la práctica en

1 Método para analizar cómo las TIC pueden afectar a la enseñanza y el aprendizaje.

2 Marco para comprender y describir los tipos de conocimiento que necesita un docente para una práctica pedagógica efectiva dentro de un entorno de aprendizaje potenciado por la tecnología. lo que a la resolución de problemas cotidianos de la práctica y el trabajo colaborativo docente se refiere. También fue destacable que la mejora de la calidad educativa que se alcanzó fue en buena parte consecuencia de que se trabajó con grupos de docentes comprometidos e interesados en realizar cambios en su práctica docente, a fin de innovar y dar respuesta a las necesidades reales que tenían en las aulas con sus estudiantes.

En ese mismo año se presentó un artículo acerca de un estudio de las percepciones del alumnado tras la integración de redes sociales colaborativas en comunidades de aprendizaje de la Universidad de Granada (España) y John Moores de Liverpool (Reino Unido). El objetivo fundamental del estudio era el de conocer el uso e integración de la red social educativa "UGR-John Moores" y valorar las posibilidades del aprendizaje colaborativo. Se encontró una buena aceptación por parte del alumnado debido, en buena parte, a que la red educativa les resultó un elemento facilitador de aprendizaje que les motivaba a la hora de generar y compartir información. Ello supuso una mejora de sus entornos personales de aprendizaje (PLE). Aun así, los autores del estudio sugirieron incorporar mejoras respecto a la planificación docente con la integración de las TIC (acción tutorial), así como actualizar la formación del alumnado en uso de herramientas tecnológicas (Torres, Díaz y Reche, 2015)

\section{Tendencias, desafíos y progresos}

La comunidad New Media Consortium (NMC) cuenta con la presencia de cientos de universidades de prestigio, colegios, museos y centros de investigación. El objetivo del NMC es el de estimular y promover la exploración y utilización de las TIC en la enseñanza y en la expresión creativa. La comunidad nació en el 2002 y es totalmente libre, sin derechos copyright. En su último informe "NMC Horizon Report 2015 K-12 Edition", desarrollado por Johnson, Adams, Estrada y Freeman (2015) y la 
colaboración total de 56 expertos, se desvelan las últimas tendencias de impacto, desafíos y progresos en relación con las TIC en la enseñanza dentro de la educación primaria, secundaria y de bachillerato.

El informe Horizon presenta una revisión sobre las seis tendencias de impacto en TIC a largo, medio y corto plazo. A largo plazo se identifican claramente dos tendencias: repensar cómo las escuelas funcionan y adoptar enfoques de aprendizaje más profundos. La primera indica que existe un movimiento enfocado en reinventar el paradigma tradicional del aula y reorganizar toda la experiencia de la escuela a través de enfoques de aprendizaje más innovadores. Destacan los métodos como el trabajo por proyectos y el aprendizaje basado en desafíos, ya que permiten a los estudiantes pasar de una actividad de aprendizaje a otra de manera más orgánica y sin limitaciones de duración de cada clase como en las escuelas tradicionales. La naturaleza multidisciplinaria de estos enfoques ha popularizado la aplicación creativa de las TIC y fomentado innovaciones en las escuelas, al mismo tiempo que se están conectando las clases con el tema de las siguientes. Debido a que estos enfoques provocan un aprendizaje más fluido y centrado en el estudiante, algunos docentes creen que los horarios deben ser más flexibles de modo que los estudiantes cuenten con más oportunidades de aprendizaje.

La segunda tendencia hace mención a que durante mucho tiempo ha habido un énfasis en los enfoques de aprendizaje profundo, mediante actividades más innovadoras con la finalidad de permitir a los estudiantes aprender para más tarde aplicar lo aprendido: el aprendizaje basado en proyectos, problemas e investigación, y los métodos que fomentan experiencias parecidas de aprendizaje más activo, tanto dentro como fuera del aula. Las tabletas y teléfonos inteligentes son cada vez más aceptados en las escuelas y en consecuencia los docentes están aprovechándolos para conectar su plan de estudios con la vida real. Estos enfoques se centran más en el estudiante permitiéndole, por un lado, tomar más control sobre su propio aprendizaje, y por otro, alcanzar un mayor grado de compromiso con la asignatura. También se evidencia que con estos enfoques los estudiantes son capaces de generar soluciones a problemas locales y globales, y comenzar a aplicarlas en sus propias comunidades.

En las tendencias a medio plazo que se desvelan en el informe Horizon se encuentran: el uso cada vez mayor del enfoque de aprendizaje colaborativo y el cambió del rol de los estudiantes que pasa de ser de consumido a ser de creador de conocimiento. El aprendizaje colaborativo, entendido como aprendizaje de pares o actividades grupales, se basa en la idea de que el aprendizaje es una construcción social. El enfoque consiste en el diseño de actividades centradas en su mayor parte en torno a cuatro principios: situar al alumno en el centro del aprendizaje, enfatizar los procesos de interacción y actividades prácticas, trabajar colaborativamente en grupos, y desarrollar soluciones para problemas del mundo real. Los modelos de aprendizaje colaborativo están dando buenos resultados en relación con la mejora de la participación y el rendimiento del estudiante, especialmente con estudiantes de bajos recursos. Los docentes también se benefician del trabajo colaborativo con colegas de profesión mediante nuevas oportunidades de desarrollo profesional y de una enseñanza más interdisciplinar. Una dimensión adicional de esta tendencia es el creciente interés por la colaboración global en línea a través de herramientas digitales que permiten una colaboración entre docentes de todo el mundo para la tarea de diseño de objetivos para planes de estudios y en el entendimiento intercultural.

La segunda tendencia a medio plazo nos muestra que un cambio está teniendo lugar en las escuelas de todo el mundo, ya que los estudiantes están explorando las asignaturas a través del acto de creación de contenidos más que el del puro consumo de información. Una 
enorme cantidad de herramientas digitales está disponible para apoyar esta transformación de la educación. Destacan las tecnologías móviles y sus aplicaciones de redes sociales con gran popularidad como Snapchat, Instagram y Vine, en las que la gente cuenta informalmente sus historias a través de fotos y vídeos. Muchos docentes creen que perfeccionar estas habilidades con las tecnologías móviles puede conducir a los estudiantes a experiencias de aprendizaje más significativas en las que se conviertan en autoridades sobre ciertos temas a través de la investigación, el diálogo y la producción. La creación y el desarrollo de videojuegos junto con la programación pertenecen a esta nueva tendencia que enriquece a los estudiantes en lo que a la invención y el emprendimiento se refiere.

A corto plazo nos encontramos con las tendencias de: aumento del uso del Blended Learning $^{3}$ (b-learning) y del aprendizaje STEAM ${ }^{4}$. Las percepciones que se tienen sobre el aprendizaje en línea son más positivas a medida que más colegios experimentan los beneficios de los modelos de aprendizaje b-learning. Los centros que adoptan estos modelos están descubriendo que los entornos de aprendizaje en línea aumentan las funciones de los centros físicos, y pueden ser utilizados potencialmente para ganar tiempo de clase que se puede destinar a otras actividades que aumenten las interacciones en ese espacio virtual. Estos modelos emergentes fomentan el aprendizaje personalizado y más comprometido por parte del alumnado.

El aumento del aprendizaje STEAM se enmarca dentro de la segunda gran tendencia a corto plazo y su filosofía consiste en que todas las disciplinas deben relacionarse entre sí para permitir que los estudiantes se formen un panorama general sobre cómo una amplia variedad

3 Aprendizaje semipresencial con entrega de material de forma digital y en línea.

4 Enfoque de aprendizaje que toma las materias de ciencias, tecnología, ingeniería, matemáticas y arte como puntos de acceso para guiar al estudiante hacia la investigación, el diálogo y el pensamiento crítico. de conocimientos y habilidades se entrelazan, al igual que acontece en la vida. En definitiva, el uso de las TIC no se refiere exclusivamente al avance de la ciencia y la ingeniería; el aprendizaje STEAM trata de involucrar a los estudiantes en un contexto de aprendizaje interdisciplinario que valore a las humanidades y a las actividades artísticas, al mismo tiempo que rompa las barreras que tradicionalmente han existido entre las diferentes clases y disciplinas.

En el informe Horizon también se identifican los principales desafíos que existen a la hora de integrar las TIC en la educación:

- Creación de auténticas oportunidades de aprendizaje que conecten a los alumnos con el mundo real y las situaciones laborales.

- La integración de la tecnología en la formación del profesorado y en los métodos de enseñanza no es muy común.

- La personalización del aprendizaje, cuyo mayor obstáculo es la dificultad para condensar los métodos y las TIC en una estrategia ágil que pueda ser implementada y reproducida en todos los centros educativos.

- Replanteamiento de las funciones de los docentes, prestando atención a la utilización habitual de las estrategias digitales en su trabajo con los estudiantes.

- La ampliación de las innovaciones pedagógicas, debido a que los colegios no son todavía partidarios de llevar la innovación pedagógica hacia una práctica más generalizada.

- La enseñanza del pensamiento complejo, para que los jóvenes puedan comprender el mundo digital en el que están inmersos y también, a través del pensamiento complejo, aprender cómo utilizar la abstracción y la descomposición a la hora de 
abordar tareas complejas.

En relación con los últimos progresos de las TIC en el marco de la enseñanza, el informe Horizon destaca los siguientes:

- Los programas Bring Your Own Device (BYOD) consistentes en permitir que los estudiantes lleven a la escuela sus ordenadores portátiles, tabletas, teléfonos inteligentes y otros dispositivos móviles en los ambientes de aprendizaje.

- Makerspaces como método para involucrar a los estudiantes en los procesos de resolución creativa de problemas a través del diseño manual, construcción e interacción con diferentes herramientas.

- La robótica, las impresoras 3D y los programas de modelado 3D.

- Las tecnologías de aprendizaje adaptativo en las que el software y las plataformas en línea se ajustan a las necesidades individuales de los estudiantes a medida que estos van aprendiendo.

- Las insignias digitales como una forma de otorgar certificados y premios al estudiante durante su aprendizaje formal o informal en forma de microcréditos, los cuales evalúan las habilidades aprendidas con base en los resultados, más que en función del tiempo dedicado.

- La tecnología portátil que se puede llevar puesta como los dispositivos en forma de joyas, gafas, zapatos, chaquetas, etc. Su beneficio radica en que permiten un seguimiento del sueño, del movimiento, de la ubicación, y de las interacciones de redes sociales. También, en el caso de las gafas Oculus Rift, se permite acceder a una realidad virtual.

Toda esta información ofrecida por la comunidad NMC pone de manifiesto que las TIC no son algo de moda y pasajero, estas han llegado a la enseñanza para quedarse. No pueden obviarse ni percibirse como estáticas, pues las tendencias nos indican que en los próximos años aumentará cada vez más su integración en los procesos de enseñanza-aprendizaje.

\section{La competencia digital}

La Unión Europea hace mención al concepto de Competencia Digital (CD). En uno de sus documentos: La recomendación del Parlamento y el Consejo Europeo publicado en el 2006 y sobre las competencias clave para el aprendizaje permanente define la competencia digital como

el uso seguro y crítico de las tecnologías de la sociedad de la Información (TSI) para el trabajo, el ocio y la comunicación. Se basaría en la adquisición de las competencias básicas en TIC: El uso de los ordenadores para obtener, evaluar, almacenar, producir, presentar e intercambiar información y comunicarse y participar en redes de colaboración usando Internet (DOUE, 2006, p. 6).

La misma recomendación del Parlamento Europeo y del Consejo en el año (Diario Oficial de la Unión Europea, 2006) sobre las competencias claves para el aprendizaje permanente señaló que la $C D$ es una de las competencias clave que los estudiantes deben haber desarrollado al finalizar la enseñanza obligatoria. Pues como se indicó anteriormente, la CD no solo proporciona la capacidad de aprovechar la riqueza de las nuevas posibilidades asociadas a las tecnologías digitales y los retos que plantean, sino que resulta cada vez más necesaria para poder participar de forma significativa en la nueva sociedad del conocimiento del siglo XXI.

Aprovechar el potencial y posibilidades que pueden ofrecer las TIC en la enseñanza demanda de docentes con destrezas digitales, es decir, que hayan adquirido la competencia digital (CD) que tanto demanda la sociedad actual. Miembros del Projecte Interdepartamental de Competència Digital Docent, como Carrera y Gisbert (2015) informaron en el último "XVIII 
Congreso Internacional Edutec en Riobamba, Ecuador" acerca de los avances en el diseño del procedimiento de acreditación en competencia digital docente (CDC) para Cataluña. En él se definió el concepto de CDC:

La capacidad que tienen los docentes de aplicar y transferir todos sus conocimientos, estrategias, habilidades y actitudes sobre las Tecnologías para el Aprendizaje y el Conocimiento (TAC) en situaciones reales y concretas de su praxis profesional con el fin de: (a) facilitar el aprendizaje de los alumnos y la adquisición de la competencia digital de este colectivo; (b) llevar a cabo procesos de mejora e innovación en la enseñanza de acuerdo con las necesidades de la era digital; $y$ (c) contribuir a su desarrollo profesional de acuerdo con los procesos de cambio que tienen lugar en la sociedad y en los centros educativos (Diario Oficial de la Generalitat de Catalunya, 2016).

\section{Metodología}

En esta investigación se pretende desarrollar teorías explicativas de la literatura existente, del sentido común, de la experiencia del propio investigador-participante, y del caso real que se estudia mediante un análisis inductivo. Por tanto, se trata de una investigación con carácter empírico y exploratorio.

La metodología cuantitativa es aquella que cuenta con técnicas confirmatorias que aportan datos estadísticos. Esta requiere de una inmersión inicial en el campo, una interpretación contextual, flexibilidad, preguntas y recolección de datos a fin de descubrir la naturaleza del mundo social a través de la comprensión de las acciones de las personas. Esta requiere de experimentación, preguntas, estadística, patrones, encuestas y recolección de datos.

También se puede encontrar la metodología mixta, esta trata de representar "un conjunto de procesos sistemáticos, empíricos y críticos de investigación e implican la recolección y el análisis de datos cuantitativos y cualitativos, así como su integración y discusión conjunta, para realizar inferencias producto de toda la in- formación recabada y lograr un mayor entendimiento del fenómeno en estudio" (Hernández, Fernández y Baptista, 2010, p. 546).

El autor Christ (2007) argumenta que la investigación mediante métodos mixtos se ha fortalecido en los últimos veinte años, y los estudios exploratorios cualitativos, seguidos de estudios confirmatorios, han sido comunes y concurrentes. Por su parte, autores como Hernández, Fernández y Baptista (2010) señalan que los diseños mixtos:

[...] representan el más alto grado de integración o combinación entre los enfoques cualitativo y cuantitativo. Ambos se entremezclan o combinan en todo el proceso de investigación, o, al menos, en la mayoría de sus etapas [...] agrega complejidad al diseño de estudio; pero contempla todas las ventajas de cada uno de los enfoques (p. 21).

Dentro de los diferentes métodos de investigación existentes se encuentra el "estudio de caso". Una de sus principales ventajas es la realización de un estudio más intensivo y profundo. Esta investigación hace un uso parcial de este método cualitativo debido a que una de las finalidades es comprender en la mayor profundidad posible la realidad del centro mediante descripciones y análisis. El estudio de caso se caracteriza por la particularización, es por ello que está orientado a comprender exclusivamente la realidad singular de este centro sin intención de generalizar hacia otros centros educativos.

Por tanto, la metodología que se establece en esta investigación es la metodología mixta, debido a que se pretende comprender en la mayor profundidad posible cuál es el estado de integración de las TIC en los procesos de enseñanza-aprendizaje del centro objeto de estudio, desde dentro mediante el método de estudio de caso y con técnicas como la entrevista y el registro de observaciones por parte del investigador-participante, y al mismo tiempo, buscando causas y explicaciones a través 


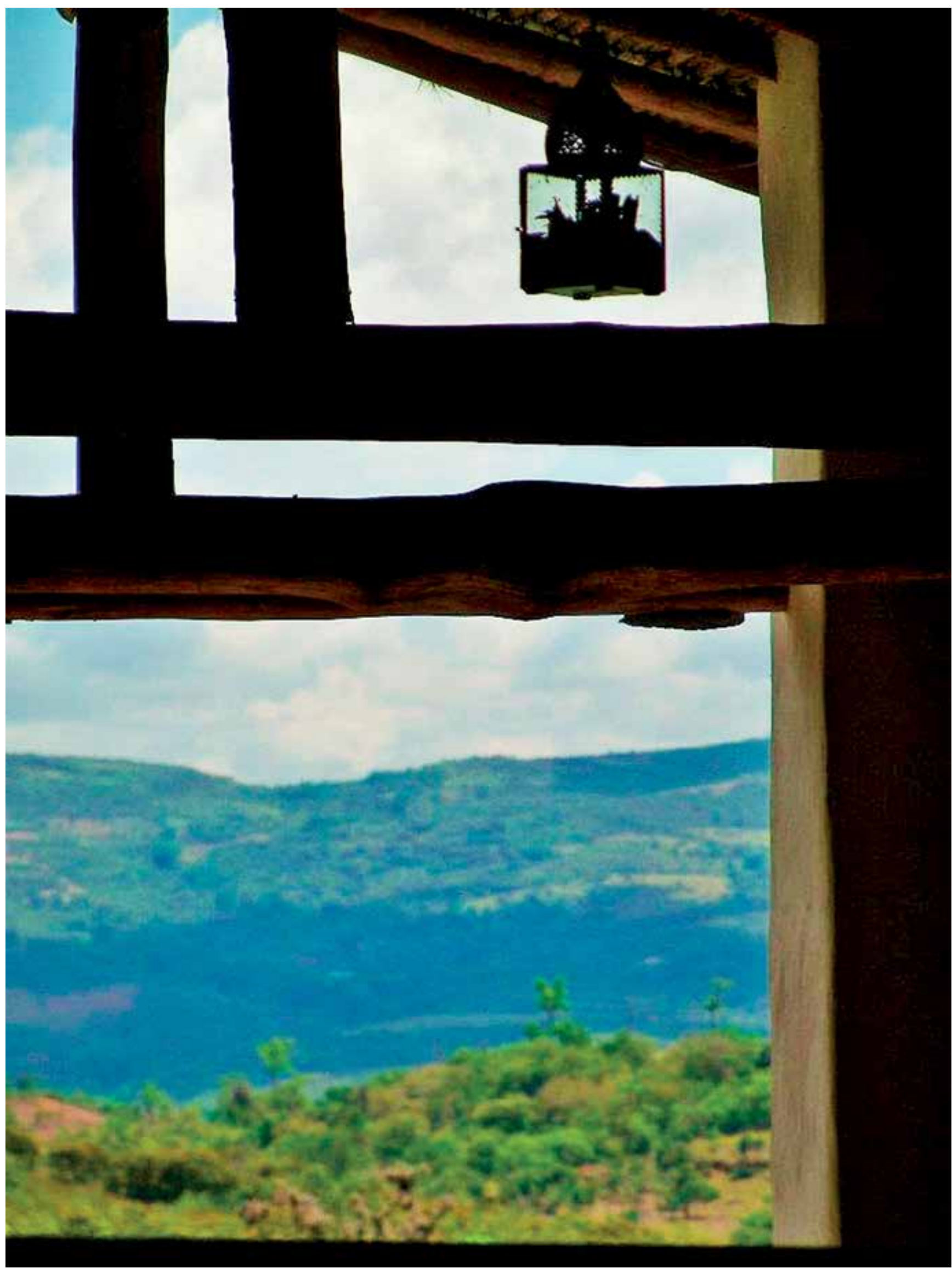


de herramientas de recogida de datos como un cuestionario validado. Una vez se analicen los resultados, se podría sugerir una serie de pautas o estrategias destinadas a mejorar la calidad educativa del centro con el apoyo de las TIC.

En definitiva y partiendo de la afirmación de Salinas (2016) acerca de que la investigación es ecléctica y no tiene obligación de encajarse en un método $u$ otro debido a que los diseños son herramientas de las que nos servimos para investigar mejor, en este proyecto se pretende llevar a cabo una investigación empírica exploratoria, con la finalidad de desarrollar teorías explicativas del caso de estudio mediante un análisis inductivo. Además, esta partiría de un paradigma interpretativo, de tipo no experimental, y estaría basada en una metodología mixta en la que se mezclan técnicas cuantitativas y cualitativas simultáneamente, es decir, datos cuantitativos y cualitativos con análisis cualitativos y cuantitativos.

Por tanto, el paradigma de investigación que orienta esta investigación es el interpretativo, ya que es dinámico y múltiple, y su finalidad es la de comprender e interpretar fenómenos. En este trabajo se utiliza una metodología mixta en el que el enfoque cualitativo y cuantitativo tiene un gran peso durante el proceso de investigación. Además, el paradigma de investigación interpretativo va a permitir interpretar, comprender, entender y diagnosticar la realidad del centro a través de los significados de las acciones, percepciones e intenciones de las personas.

El diagnóstico sobre el estado de integración de las TIC en los procesos de enseñanza-aprendizaje del centro requiere de unas dimensiones en las que basarse:

Infraestructura escolar: la cual "ha sido tradicionalmente analizada como un factor asociado ante todo con la cobertura escolar. Sin embargo, recientemente ha aumentado el número de estudios que han encontrado asocia- ciones positivas entre las condiciones físicas de las escuelas y el aprendizaje de los estudiantes" (Duarte, Moreno y Gargiulo, 2011, p. 2). Por tanto, se debe prestar atención a la siguiente definición de indicadores para el estudio de esta dimensión:

- Aulas de computación para alumnos: número de aulas y computadoras, y características técnicas de las computadoras.

- Salas de computación para docentes: número de salas y computadoras, y características técnicas de las computadoras.

- Calidad de la conexión a internet: estabilidad, velocidad y disponibilidad de conexión a internet, número de usuarios con acceso a la conexión y número de puntos de acceso inalámbricos y alámbricos.

- Servicios de intranet para docentes: estabilidad del servidor, si la interfaz es intuitiva $y$ amigable, y tipos de funcionalidades que ofrece.

- Disponibilidad de software: tipo y número de licencias de software compradas.

- Disponibilidad de hardware: número de tabletas, proyectores de vídeo y equipos de reproducción de audio.

Equipamiento del docente: entendido como el conjunto de elementos de software y hardware con los que cuenta el docente para realizar una interacción de las TIC en los procesos de enseñanza-aprendizaje. A partir de ello se pueden definir los indicadores:

- Disponibilidad de software: se encontrarían los sistemas operativos, los programas informáticos didácticos para asignaturas, las suites de ofimática, los programas edición de vídeo y audio.

- Disponibilidad de hardware: como los ordenadores portátiles para docentes, proyectores de vídeo, equipos de audio y 
pizarras digitales para uso docente.

- Sistema de seguridad tecnológica: programas antivirus que protegen los ordenadores portátiles de los docentes frente a amenazas de virus, troyanos, malware, entre otros.

Competencia digital docente: comprendida como

el uso seguro y crítico de las tecnologías de la sociedad de la información (TSI) para el trabajo, el ocio y la comunicación. Se sustenta en las competencias básicas en materia de TIC: el uso de ordenadores para obtener, evaluar, almacenar, producir, presentar e intercambiar información, y comunicarse y participar en redes de colaboración a través de Internet (DOUE, 2006, p. 6).

A partir de la definición anterior se focaliza su estudio en los siguientes indicadores:

- Formación en TIC: permite conocer si los docentes han recibido formación específica en TIC o si por el contrario necesitan o demandan formación en TIC.

- Destrezas en informática: utilización de dispositivos digitales y conocimiento sobre ordenadores, cámaras de fotos y vídeo.

- Uso de las TIC en el aula: la autora Mayenco (2009) destaca el acceso inmediato a fuentes de información y recursos a través de los buscadores, acceso también inmediato a canales de comunicación como el correo electrónico, chat y foros, creación de recursos con la ayuda de suites de ofimática, editores de imágenes, audios y vídeos (Movie Maker), diseño de páginas web, programas de uso frecuente (antivirus, Skype, aTube Catcher, Mimio Studio, Google Drive para escritorio y Prezi), y no menos importante, la utilización de recursos educativos en páginas web, plataformas b-learning, y proyectores de vídeo.
- Desarrollo de innovaciones educativas: conocer si existen docentes que hayan puesto en práctica actividades de innovación educativa con sus alumnos.

La actitud del docente hacia las TIC: Lucena, Martín y Díaz (2002) realizaron un estudio sobre las actitudes que los docentes tienen en relación con la formación en TIC aplicadas a la educación. Entre ellas se encuentran y destacan para esta investigación la actitud hacia la aplicabilidad de las TIC en las diferentes asignaturas y la actitud hacia la importancia de la formación permanente sobre el uso de las TIC en la enseñanza. Por tanto, se definen los siguientes indicadores:

- Valoración de las TIC como recurso: percepciones y opiniones que tienen los docentes sobre las TIC como recurso para la enseñanza.

- Visión a futuro de la integración tecnológica en la institución: opiniones o pronósticos de los docentes en relación con el futuro de la integración de las TIC a nivel institucional.

- Inquietud de los docentes respecto a su formación en las TIC: todas las preocupaciones que tengan los docentes en lo que se refiere a su formación en TIC.

- Necesidades de los docentes en relación a las TIC en la enseñanza: requerimientos que los docentes puedan tener para integrar las TIC en la enseñanza.

Una vez definido lo anterior, se presta especial atención a las diferentes técnicas cuantitativas y cualitativas disponibles para la recogida y análisis de datos. Entre ellas se encuentra la encuesta. Esta no necesita de personas preparadas para la recogida de información, se puede enviar y aplicar online, y las respuestas del entrevistado pueden ser más meditadas debido a la ausencia de restricciones de tiempo. También cuenta con algunas desventajas como 
que las respuestas sean afectadas por el estado de ánimo del entrevistado, contestarlo requiere de cierto nivel de comprensión y expresión, y no se puede garantizar que todos los cuestionarios enviados online sean respondidos.

En este trabajo se aplica un cuestionario a todos los docentes de la institución que cuenta con preguntas derivadas de cuestionarios validados junto con preguntas específicas que solicitaron las autoridades académicas del centro. La herramienta que se utilizó para la aplicación del cuestionario en modalidad online fue Google Forms debido a que además de ser gratuita, genera automáticamente reportes estadísticos que posibilitarían el análisis de los datos. Las siguientes preguntas corresponden al cuestionario y el enlace web (https://onedrive.live.com/re dir? resid=8EB8D616D5EADB8B!4490\&authkey= !AEAcjFyymDBv9rY\&ithint=file\%2cpdf), el cuestionario completo se muestra a continuación:

1. ¿En qué sección imparte sus clases?

2. La computadora que uso regularmente para mis tareas docentes es:

3. ¿Utiliza la computadora exclusivamente para tareas docentes?

4. ¿Con qué frecuencia utiliza su computadora?

5. ¿Con qué frecuencia utiliza el proyector de vídeo en sus clases?

6. ¿Qué usos le da al proyector en clase?

7. ¿Cómo calificaría la conexión a internet de su institución?

8. ¿Cuál es el sistema operativo de su computadora?

9. ¿Qué suite de ofimática tiene instalada?

10. Marque aquellos programas que tenga instalados en su computadora.
11. Mencione otros programas que tenga instalados en su computadora.

12. Califique su nivel de competencia para los siguientes programas.

13. Indique las cinco páginas web o plataformas que más utiliza.

14. ¿Cuál es su opinión acerca del uso de las TIC en la enseñanza?

15. Valore su interés por las TIC en la enseñanza.

16. Califique su nivel de competencia o destreza técnica en informática.

17. Califique su nivel actual de competencia o destreza digital en la enseñanza.

18. Indique si ha puesto en práctica alguna actividad de innovación educativa con sus alumnos.

19. ¿Considera que necesita formación en el uso de las TIC?

20. Diga si es capaz de realizar las siguientes acciones.

21. Indiqué sus necesidades o inquietudes tecnológicas.

En la tabla 2 se justifica el origen en el cual se basan las preguntas presentes en el cuestionario, su relevancia para otros autores y su relación con las dimensiones planteadas con anterioridad.

La información obtenida en la aplicación de este cuestionario de todos los docentes de la institución es de gran utilidad para el diagnóstico de la integración de las TIC en el centro, y para la elaboración de unas pautas de mejora de la calidad de la enseñanza del centro, apoyándose en las nuevas tecnologías. 
Tabla 2. Relación de preguntas con cuestionarios validados

\begin{tabular}{llll} 
NN$^{\circ}$ & Origen & Relevante para otros autores & Dimensión \\
\hline 1 & Autoridades académicas del centro & Ninguna (datos personales) \\
\hline 2 & Autoridades académicas del centro & Equipamiento docente \\
\hline 3 & Autoridades académicas del centro & Competencia digital docente \\
\hline 4 & Autoridades académicas del centro & - Valdez (2011) & Competencia digital docente \\
\hline
\end{tabular}

Encuesta para profesores sobre el uso de las tecnologías

5 de la información y la comunicación, TIC. Universidad Nacional Autónoma de México. Facultad de Ingeniería, División de Ciencias Básicas (Valdez, 2011).

Competencia digital docente

Uso de los recursos tecnológicos en las aulas inteligentes que dan los profesores de la preparatoria del Tecnológico de Monterrey, Campus Hidalgo (Martínez y Urbina, 2008).

- Valdés, Angulo, Urías, García y

Mortis (2011)

- López (2010)

Competencia digital docente

7 Autoridades académicas del centro Infraestructura escolar

8 Autoridades académicas del centro Equipamiento docente

9 Autoridades académicas del centro Valdez (2011) Equipamiento docente

10 Autoridades académicas del centro - Álvarez y Gisbert (2015)

- Valdez (2011)

Equipamiento docente

11 Autoridades académicas del centro

- Valdez (2011)

- Álvarez y Gisbert (2015)

Equipamiento docente

- Carrera, Vaquero y Balsells

12 Autoridades académicas del centro

(2011)

- Valdez (2011)

Competencia digital docente

- Álvarez y Gisbert (2015)

Aplicación de plataformas virtuales LCMS en la materia

13 de técnicas de estudio para determinar nuevas metodologías de aprendizaje en educación a distancia. (Ofelia, 2011)

Necesidades de capacitación de docentes de educación

14 básica en el uso de las TIC. Valdés, Angulo, Urías, García y Mortis (2011)

- López (2010)

- Lucena, Martín y Díaz (2002)

- RedXXI Educacyl Digital (s.f)

- RedXXI Educacyl Digital (s.f)

López (2010)

16 Autoridades académicas del centro

Grado de alfabetización informacional del profesorado

17 de Secundaria en España: Creencias y autopercepciones (Álvarez y Gisbert, 2015)

Las percepciones de los profesores respecto a

18 la investigación e innovación en sus contextos profesionales (Larenas, Solar, Hernández y Solar, 2015)

Las actitudes de los docentes hacia la formación en

19 tecnologías de la información y comunicación aplicadas a la educación (Lucena, Martín y Díaz, 2002).

Instrumento de evaluación de competencias digitales

20 para adolescentes en riesgo social (Carrera, Vaquero y Balsells, 2011).

$21 \quad$ Autoridades académicas del centro

RedXXI Educacyl Digital (s.f)
Competencia digital docente

Competencia digital docente

La actitud del docente hacia las TIC

La actitud del docente hacia las TIC

Competencia digital docente

Competencia digital docente

La actitud del docente hacia las TIC

Competencia digital docente

La actitud del docente hacia las TIC 
La técnica de investigación de la entrevista se diseña de modo semiestructurada alternando preguntas estructuradas con espontáneas. Así se profundiza en las características específicas de los sujetos entrevistados, los docentes del centro, y se la dota de mayor libertad y flexibilidad.

En la institución laboran tres coordinadoras académicas, una para cada sección: preescolar, primaria y secundaria. El contacto diario entre las coordinadoras y sus docentes las provee de gran información tanto documentada como observada, que puede ser de utilidad para profundizar en algunos indicadores. Es por ello que la aplicación de la técnica de la entrevista a las coordinadoras académicas es una valiosa fuente de información.

Por otro lado, la participación del investigador como observador y coordinador de TIC en activo del centro posibilita la aplicación de la técnica de observación y el acceso a documentos institucionales relevantes para este estudio. Por tanto, estas técnicas cualitativas aportan información para estudiar múltiples y variados aspectos que más tarde son analizados y comparados con otros, al tiempo que son vistos dentro de sus propios ambientes. Se plantea el procedimiento empírico de observaciones en el cual el investigador participante se relaciona con la realidad del centro objeto de estudio. Mediante la observación se obtiene, por un lado, información que no se recaba del resto de técnicas de esta investigación, y por otro, se profundiza sobre algunas de las dimensiones e indicadores.
Por último, también se realiza una revisión de documentos institucionales como técnica de observación complementaria. Con ella se puede acceder a información más difícil de obtener a través de las técnicas anteriores y a otra que confirme o ponga en duda los datos obtenidos de las entrevistas y el cuestionario. Entre los documentos por revisar se encuentran el informe estado de conexión a internet, el inventario institucional y las planificaciones de unidades didácticas de cada sección. En la tabla 3 de identifican los documentos que se revisan y su relación con algunas de las dimensiones e indicadores.

\section{Resultados obtenidos y esperados}

Los resultados de la primera fase de investigación, dan cuenta de la aplicación del cuestionario a todos los docentes del centro y de la revisión documental. Aun así, se describen los datos que se espera recolectar de la aplicación del resto de técnicas cualitativas en la futura segunda fase de la investigación.

\section{Del cuestionario}

De los resultados del cuestionario aplicado se obtiene información relevante para el estudio. En la tabla 4 se muestra información sobre la propiedad de los ordenadores que utiliza el profesorado del centro para su desempeño docente.

La frecuencia de uso del proyector de vídeo en clase se midió en una escala del 1 al 5 y se encontró que un $38.5 \%$ de los encuestados utilizaba el proyector siempre que tenían clase frente a un $4 \%$ que no lo utilizaba nunca. Los resultados completos se muestran en la figura 1.

Tabla 3. Documentos de revisión y su relación con dimensiones e indicadores

Documento

1. Informe estado de conexión a internet.

2. Planificaciones de unidades didácticas de cada sección.
Dimensión

Infraestructura escolar

Competencia Digital
Indicador

Calidad de la conexión a internet

Desarrollo de innovaciones educativas 
Tabla 4. Propiedad de los ordenadores de uso docente

\begin{tabular}{cc} 
Propiedad & Porcentaje \\
\hline Del propio docente & $55.6 \%$ \\
\hline Subvencionada por el centro & $21.4 \%$ \\
\hline Del centro & $21.4 \%$ \\
\hline No dispone & $1.6 \%$ \\
\hline
\end{tabular}

Entre los principales usos que los encuestados dan al proyector destacan la reproducción de vídeos (115), presentaciones multimedia (59), imágenes (24), y ejercicios y contenidos musicales (24, respectivamente).

Otro dato relevante fue la baja calificación que los encuestados dieron a la conexión a internet, pues más de la mitad la calificó como deficiente (figura 2).
Como se puede apreciar en la figura 3, casi la mitad de los docentes contaba con Windows 8 como sistema operativo y llama especialmente la atención que el 19.2\% desconocía qué sistema operativo tenía instalado. Por otro lado, la suite de ofimática Microsoft office 2010 se consolidó como la suite de ofimática más utilizada, seguida de la versión 2013 y vuelve ser notorio que el $26 \%$ lo desconocía.

Figura 1. Frecuencia de uso del proyector de video.

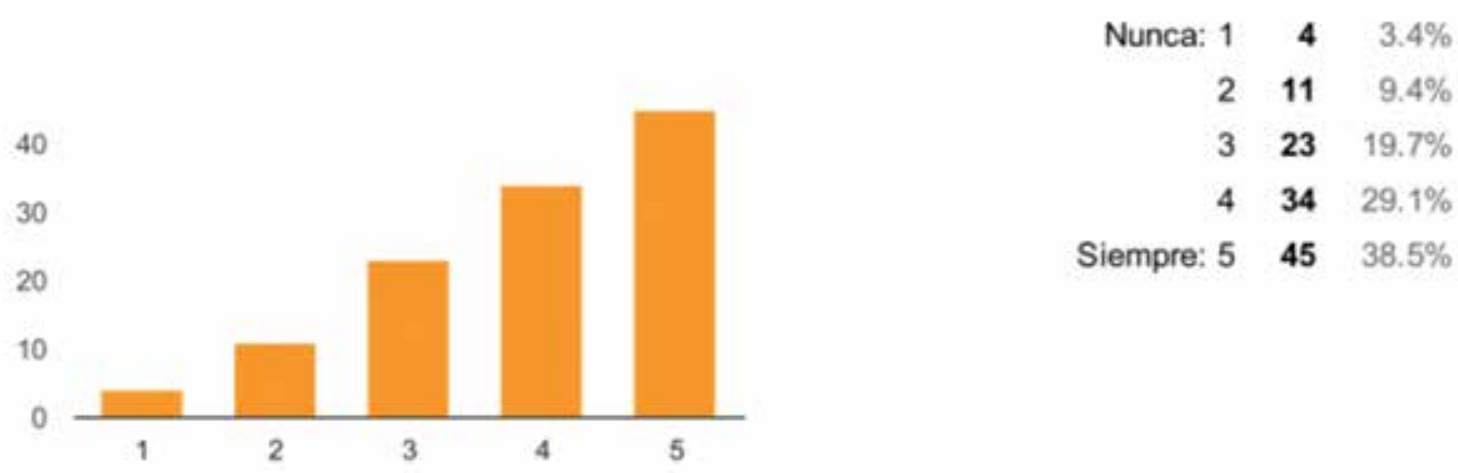

Figura 2. Valoración de la conexión a internet del centro.

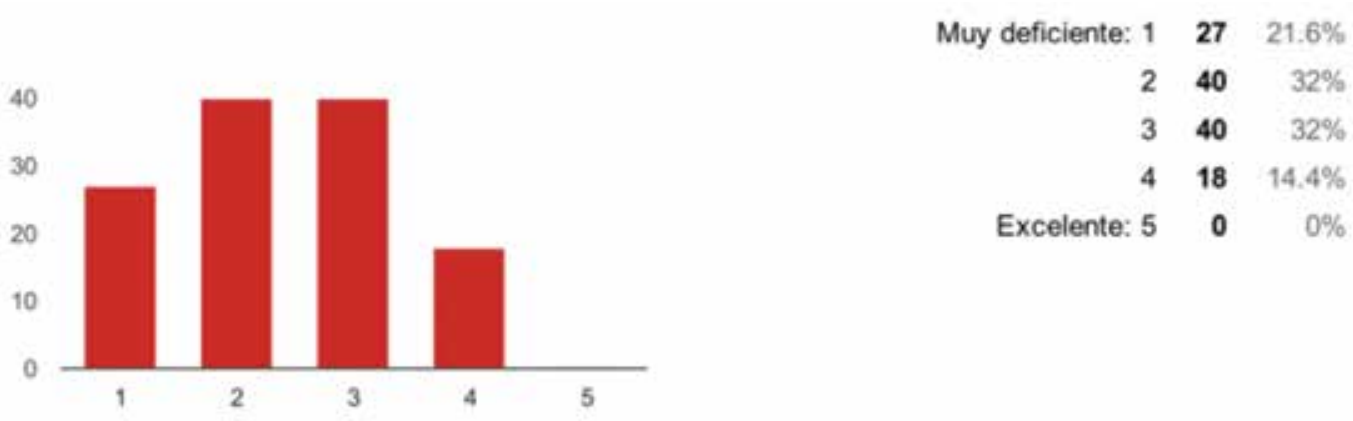


Figura 3. Sistema operativo y suite de ofimática.

¿Cuál es el sistema operativo de su computadora?

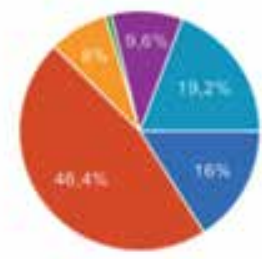

¿Qué suite de ofimática tiene instalada?

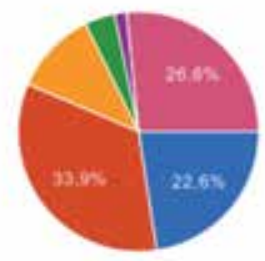

Microsoft Office 2013

Microsoft Office 2010

Microsoft Office 2007

iWork de Mac

Otra

No tengo ninguna sulte instalada

Lo desconozco

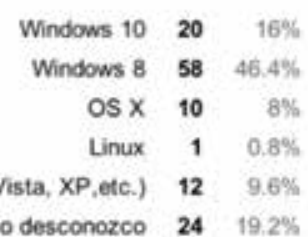

$\begin{array}{lll}\text { Lo desconozco } \quad 24 \quad 19.2 \% & 0.6 \%\end{array}$
En relación con los programas de uso frecuente que tenían instalados se halló que la mayoría de computadoras tenía Google Drive, antivirus Avast y Skype. Obsérvese en la tabla
5 el número de docentes que tenía instalado cada programa y el dato más llamativo en relación con el nivel docente de competencia en el manejo de cada programa.

Tabla 5. Programas instalados en ordenadores de docentes

\begin{tabular}{ccc} 
Programa & $\begin{array}{c}\text { No docentes que lo } \\
\text { tienen instalado }\end{array}$ & Nivel de competencia \\
\hline Google Drive & 87 & $76.6 \%$ - Competente básico \\
\hline Antivirus Avast & 67 & $28.6 \%$ - Competente básico \\
\hline Skype & 57 & $38.7 \%$ - Competente medio \\
\hline Movie Maker & 33 & $30.4 \%$ - Competente medio \\
\hline Mimio Studio & 32 & $42.6 \%$ - Competente básico \\
\hline aTube Catcher & 32 & $41 \%$ - Desconocido \\
\hline Prezi & 19 & $31.7 \%$ - Competente básico \\
\hline Audacity & 8 & $72.9 \%$ - Desconocido \\
\hline SmartMusic for Educators & 5 & $85.1 \%$ - Desconocido \\
\hline Molecular Workbench & 3 & Desconocido \\
\hline
\end{tabular}


De todas las plataformas o páginas web que indicaron como de uso frecuente en su práctica docente destacaron YouTube, Gmail, Pinterest, Reading A-Z, Hotmail y Edmodo (figura 4).

En relación con la opinión del profesorado sobre el uso de las TIC en la enseñanza actual es de destacar que para la mayoría estas son indispensables en todas las facetas. Además, algo más de la mitad de los encuestados valoró con un 4 (escala 1-5) su interés por las TIC en la enseñanza (figura 5).
La autovaloración de la competencia o destreza técnica en informática y la competencia o destreza digital docente se situó en niveles medios. En la figura 6 se pueden visualizar los resultados obtenidos.

El 41.3\% señaló que necesita formación TIC en un buen número de herramientas y el $31.7 \%$ un programa integral de capacitación en TIC (figura 7).

Figura 4. Plataformas y páginas web de uso docente.

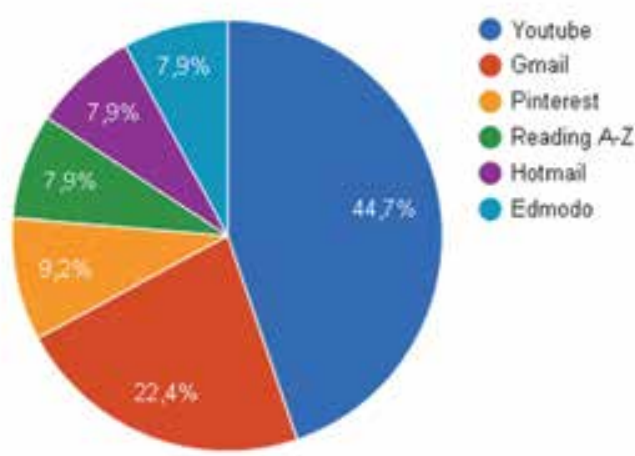

Figura 5. Opinión e interés del profesorado por las TIC.

¿Cuál es su opinion acerca del uso de las TIC en la enseñanza?
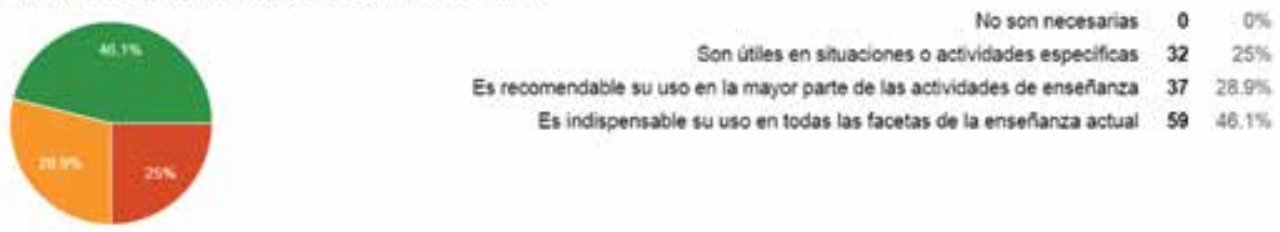

Valore su interés por las TIC en la enseñanza
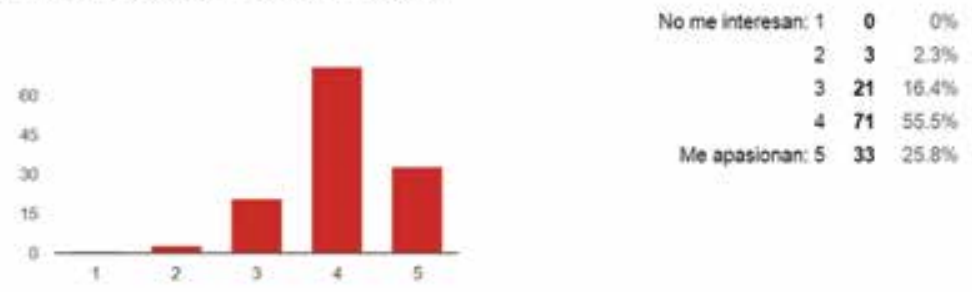

Me apasionan: $533 \quad 25: 8 x$ 
Figura 6. Competencia técnica y digital docente.
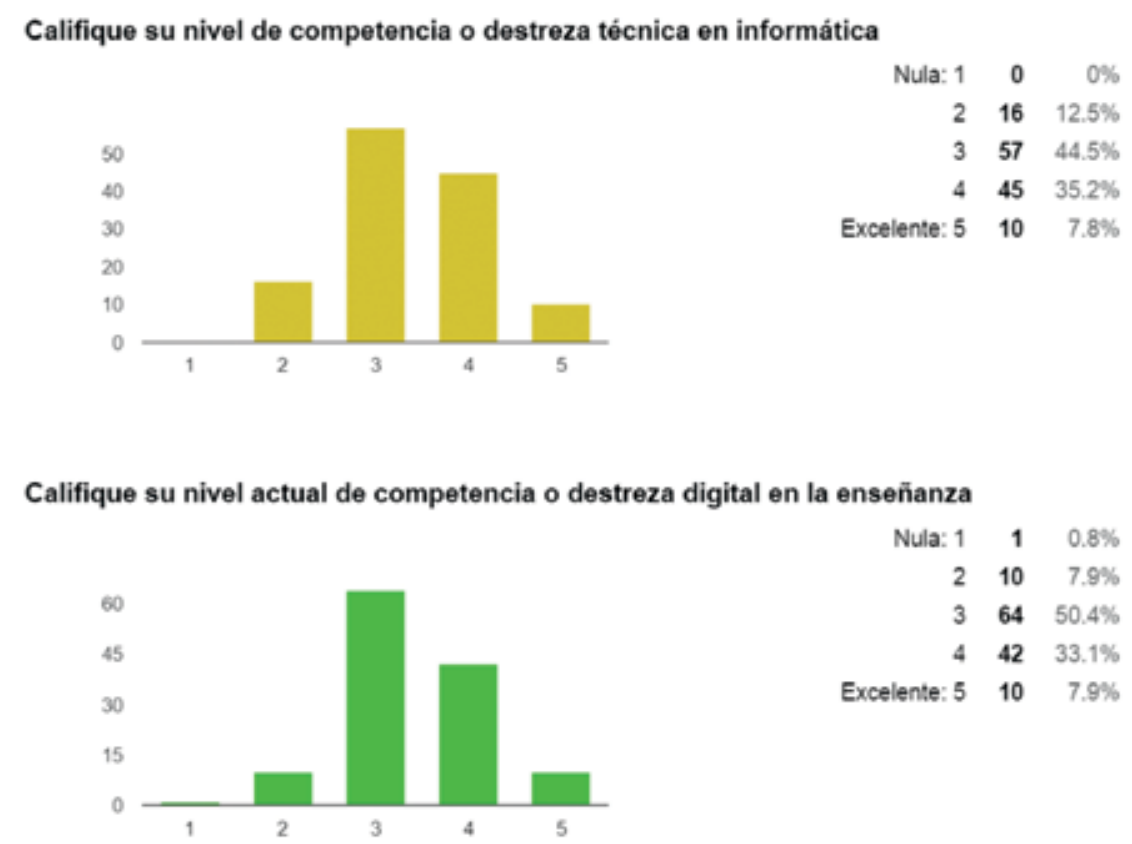

Figura 7. Necesidades de formación en TIC.

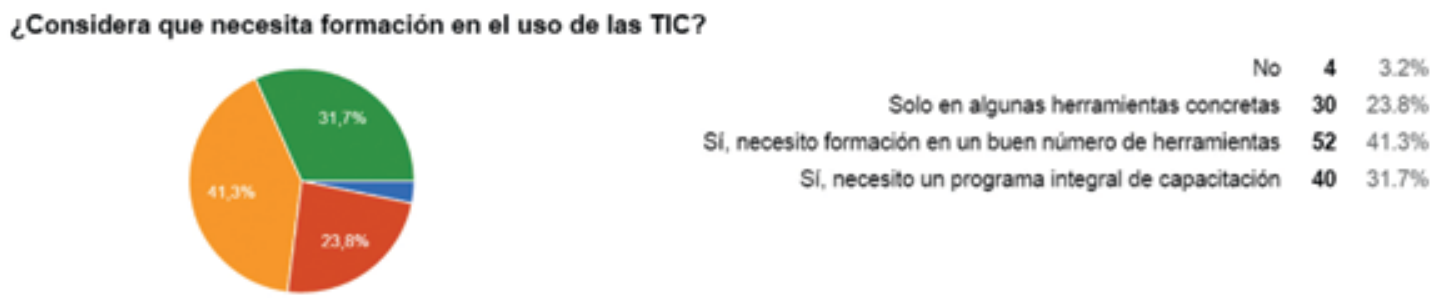

En los ítems relativos a la autocalificación acerca de la capacidad de realizar tareas tecnológicas frecuentes se obtuvieron los siguientes resultados relevantes:

- El 79.3\% es capaz y sabe explicar cómo encender y apagar una computadora, celular o cámara de fotos.

- El $97.6 \%$ es capaz de guardar y transferir información entre dispositivos.

- El $20.8 \%$ no es capaz o desconoce si una computadora es mejor que otra.
- El $88.3 \%$ reconoce las palabras más comunes de un sistema operativo.

- El $84.8 \%$ (36.1\% con ayuda) es capaz de eliminar un virus de su computadora.

- El $95.9 \%$ (15\% con ayuda) es capaz de configurar elementos básicos de la computadora.

- El $81.8 \%$ capaz (26.4\% con ayuda) es capaz de instalar una impresora y cambiar la tinta.

- El $93.4 \%$ (14\% con ayuda) es capaz de conectar equipos de audio, proyectores, cámara de video o fotos a la computadora. 
Finalmente, y en relación con las necesidades e inquietudes tecnológicas de los docentes, unos 34 encuestados señalaron la necesidad de capacitaciones tecnológicas. Unos 7 encuestados demandaron equipos técnicos, tales como: proyectores, parlantes y conexión HDMI. La necesidad de contar con internet estable es solicitada por 6 encuestados. Adquirir licencias para plataformas b-learning y software educativo fue también demandado por 6 de los encuestados.

\section{De la revisión documental}

Se realizó revisión del último informe de estado de la conexión a internet en el centro, a fin de determinar la calidad de la conexión. También se revisaron 9 planificaciones de unidades didácticas y una planificación anual de algunas de las asignaturas que se imparten en cada una de las tres secciones de la institución. En la tabla 6 se puede encontrar la información relevante que se obtuvo.

\section{Tabla 6. Resultados de revisiones documentales}

El informe recoge y sintetiza diferentes opiniones y comentarios aportados por empleados de cada departamento o sección de la institución en relación con la calidad de la conexión a internet, durante el periodo del lunes 4 de abril al viernes 15 de abril de 2016. En la sección de Preescolar no se encontró problemas de conexión. En Primaria tampoco se encontraron problemas de conexión a internet y los docentes manifestaron que encontraron una mejoría en comparación con la calidad de conexión de meses anteriores. En la sección Secundaria se encontraron opiniones diversas:

El Departamento de Matemáticas reportó inestabilidad y caídas de la conexión dentro de su sala de trabajo. Así mismo, indicaron que se produjeron caídas parciales, es decir, una fila de computadoras de su oficina se quedaba sin conexión mientras que la otra sí tenía, y viceversa. El Departamento de Ciencias sufrió caídas de la conexión dos días.

El Departamento de Inglés reconoció una mejora sustancial, tanto en estabilidad como en velocidad de internet, aunque manifestaron que el aula de $1^{\circ}$ Bach. continúa presentando problemas de conexión.

El Departamento de Humanidades se encontró con inestabilidad de la red, tanto en su oficina como

1. Informe de estado de conexión a internet en el centro en las aulas de clase dos días. También indicaron que la velocidad de navegación es normalmente lenta en su oficina.

El Área de Francés solo tuvo problemas de acceso a Gmail, Google Drive y YouTube dos días. Además, indicaron que en todas las aulas de décimos grados casi nunca tienen acceso a internet.

Para el Departamento de Arte la conexión fue óptima, a excepción del acceso al portal de calificaciones Rutademic y a Gmail que presenta problemas a diario.

Para uno de los docentes de Música, la conexión funcionó adecuadamente pero eventualmente sufrieron caídas tanto en las aulas como en su departamento.

En lo que respecta al Departamento de Español, algunas caídas de la red ocurrieron en las dos semanas, además de tener dificultades durante el proceso de aplicación de controles de lectura al alumnado debido a la lentitud de la velocidad de Internet.

También se comunicaron incidencias en el aula Mediateca, una caída general uno de los días, y el diagnóstico fue de puertos quemados en el servidor de la propia aula que afectaron a una de las computadoras.

Una feria de exposición y defensa de proyectos se llevó a cabo durante dos días y en la misma se habilitó el acceso a internet a las computadoras de algunos alumnos que defendían su trabajo. En ambos días se reportaron caídas de la conexión y lentitud de navegación por parte de varios profesores de secundaria.

2. Planificación de unidad didáctica 5 de Francés de $8^{\circ}$ básica en secundaria

Si bien se encuentra que el docente utiliza un CD multimedia, videos e imágenes de internet con fines didácticos, no se encuentran verdaderas actividades o experiencias de innovación educativa.

3. Planificación de unidad didáctica 1 de $10^{\circ}$ básica de Lengua y Literatura en secundaria
Se encuentra que el docente utilizó dos videos sobre "recuento del conflicto entre palestinos e israelíes en Gaza" y "El conflicto de Oriente Medio en 5 minutos" para generar debates y reflexiones grupales en clase. 
4. Planificación de unidad didáctica 5 de Design de $10^{\circ}$ básica de la sección en secundaria
En el documento se encuentra el diseño de una actividad de aprendizaje apoyada en las TIC. Los estudiantes trabajaron habilidades de creación y edición de videos mediante el diseño de un video informativo usando las herramientas online Edu Creations, Video Scribe, PowToon, Raw Shorts o Moovly.
5. Planificación de unidad didáctica 6 de Technology de $1^{\circ}$ Bach. en secundaria
El documento contiene un proyecto de fin de año en el que los estudiantes imaginaron que eran emprendedores, iban a abrir un negocio y debían dar solución a las siguientes necesidades mediante el uso de las TIC trabajadas durante todo el año académico:

- Investigar en internet sobre los productos y servicios que ofrecería su empresa, técnicas publicitarias, recursos humanos, etc. Redactar los hallazgos en un informe mediante un procesador de textos como Microsoft Word o Google Docs.

- Dar presencia a la empresa en internet mediante la creación de una página web con la ayuda de la plataforma online Wix.com.

- Una presentación multimedia que represente la misión y visión de la empresa mediante herramientas Micorsoft, Powerpoint, Prezi, Videoscribe o Powtoon.

- Diseñar la organización estructural de la empresa (empleados, clientes, proveedores, productos, servicios, etc.) con la ayuda de la herramienta de creación de mapas conceptuales Cmaps.

- Localizar una buena ubicación para la empresa mediante la herramienta online Google Maps.

- Crear un póster publicitario multimedia con la plataforma online Glogster.

- Diseñar un video promocional con la ayuda de una cámara digital y el software de edición de vídeo Windows Movie Maker.

- Crear una galería de arte con imágenes de los diferentes productos y servicios de la empresa mediante la web ArtMajeur.

- Creación de imágenes digitales de los productos y servicios mediante el software Photoshop.
6. Planificación de unidad didáctica 2 de Química de $1^{\circ}$ Bach. en secundaria
En esta unidad se encuentra un proyecto interdisciplinar con la asignatura de Technology. En el proyecto los alumnos debían investigar en internet cómo separar un conjunto de mezclas mediante diversos procesos de separación sin perder ningún componente y utilizando diferentes instrumentos de separación estudiados en clase. Se les pidió a los estudiantes que utilizaran las horas de Technology para investigar con los ordenadores de la aula Mediateca y que redactasen un informe de laboratorio que respetase la normativa APA, ed. 6.
7. Planificación de unidad didáctica 5 de Technology de $6^{\circ}$ básica en primaria

8. Planificación de unidad didáctica 6 de Sociales de $4^{\circ}$ básica en primaria
Se halla una actividad de aprendizaje por grupos centrada en el desarrollo de habilidades de creación de presentaciones multimedia mediante la herramienta Microsoft PowerPoint. Se les pidió a los alumnos que diseñasen una presentación relacionada con los sistemas del cuerpo humano.

Se trata de una unidad de investigación por grupos sobre la temática de los niños son ciudadanos y tienen derechos y responsabilidades. En la unidad se identifican numerosos vídeos como recursos del docente para presentar contenidos. También se encuentra una tarea consistente en usar tabletas digitales y la plataforma de lectura Reading A To Z con la finalidad de que los estudiantes lean dos libros relacionados con la temática de la unidad.

9. Planificación de unidad didáctica 6 de Inglés $3^{\circ}$ básica en primaria

Se trata de una unidad de investigación por grupos sobre la temática de cómo las personas expresan su creatividad de diferentes formas. Solo se encuentra en uso de vídeos explicativos como apoyo al docente pero sin especificar el origen y fuente de los mismos.

10. Planificación de unidades didácticas anuales de Preescolar nivel 2
No se encuentran actividades apoyadas en las TIC durante el primer quimestre, seguramente se debe a que hasta inicios del segundo quimestre, las aulas del nivel 2 de preescolar no contaban con centros de computación dentro de su aula. En el segundo quimestre sí se evidencia el uso de los centros de computación con fines de colorear animales, uso del software Paint para pintar, colorear y cortar figuras, y uso de vídeos educativos por parte del docente.
11. Planificación de unidad didáctica 6 de Preescolar nivel 1
En la planificación se distinguen actividades asignadas para uso de los centros de computación. Se encuentra planificado que los niños jueguen en línea diferentes juegos que trabajen la memoria. 


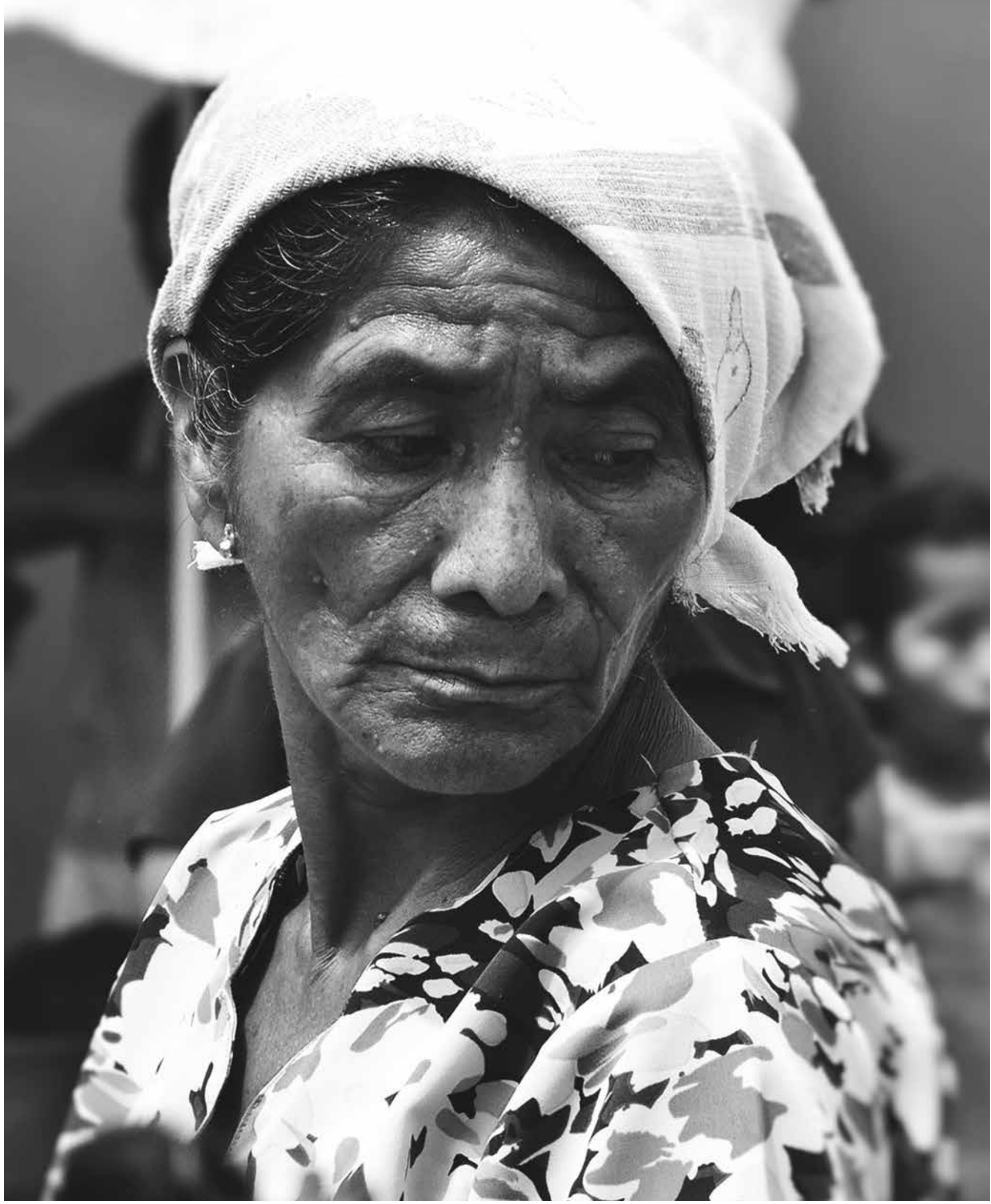




\section{De las entrevistas}

En la segunda fase de la investigación está previsto aplicar la técnica de le entrevista. De la misma se espera conseguir información de los docentes en relación con:

- La opinión que tienen sobre la intranet de la institución.

- La formación académica, cursos, diplomas, webinars, etc., que han recibido en relación con las TIC.

- Su pronóstico sobre lo que ocurrirá a futuro en la institución en relación con la integración de las TIC en la enseñanza.

- Las inquietudes o preocupaciones en relación con su formación en TIC.

- Las necesidades para lograr una mayor integración de las TIC en la enseñanza de su materia.

También se espera hacerle una entrevista al coordinador de sistemas informáticos del centro enfocada en obtener información relativa a:

- La velocidad de navegación que tiene cada sección de la institución.

- La estabilidad de la conexión a internet.

- El número de conexiones que soporta la infraestructura de red y cuántas conexiones hay activas en este momento.

- El número de puntos de acceso inalámbricos y alámbricos que tiene en operación la institución.

- La existencia de aulas o espacios sin acceso a internet.

- Las licencias de software que tiene comprada la institución.

- El número de tabletas para alumnos que hay disponibles.
- El número de proyectores de vídeo para docentes disponibles.

- El número de equipos de reproducción de audio disponibles.

En la institución laboran tres coordinadoras académicas, una para cada sección: preescolar, primaria y secundaria. El contacto diario entre las coordinadoras y sus docentes las provee de gran información tanto documentada como observada que puede ser de utilidad para profundizar en algunos indicadores. Es por ello que la aplicación de la técnica de la entrevista a las coordinadoras académicas es una valiosa fuente de información. Las preguntas deben ir dirigidas a obtener información sobre:

- Las actividades o ideas de innovación educativa que han podido evidenciar por parte de sus docentes.

- Consideraciones sobre cómo se podría lograr que sus docentes desarrollen más innovaciones educativas.

- El pronóstico sobre lo que ocurrirá a futuro en la institución en relación con la integración de las TIC en la enseñanza.

- Las inquietudes y preocupaciones en relación con su formación en TIC.

- Las necesidades para poder realizar una mayor integración de las TIC en la enseñanza de su materia.

\section{De las observaciones}

En la segunda fase de la investigación también se espera aplicar la técnica cualitativa de la observación. La participación del investigador como observador y coordinador de TIC en activo del centro posibilitaría la aplicación de la técnica de observación y el acceso a documentos institucionales relevantes para este estudio. Por tanto, estas técnicas cualitativas aportan información para estudiar múltiples y variados aspectos que más tarde son analizados y 


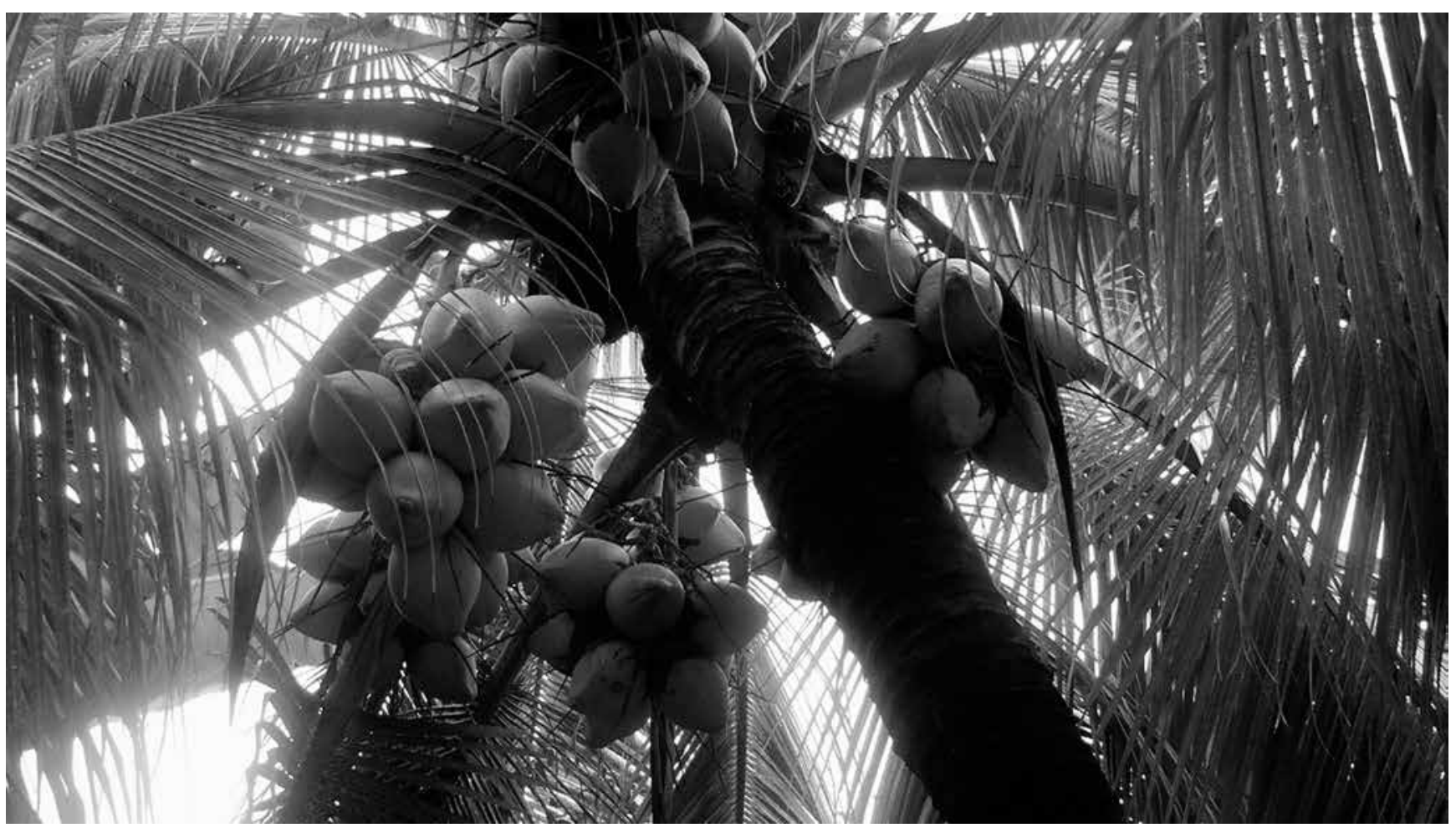

comparados con otros al tiempo que son vistos dentro de sus propios ambientes.

En primer lugar se plantea el procedimiento empírico de observaciones en el cual el investigador participante se relaciona con la realidad del centro objeto de estudio. Mediante la observación se obtiene, por un lado, información que no se recaba del resto de técnicas de esta investigación, y por otro, se profundiza sobre algunas de las dimensiones e indicadores. Mediante esta técnica se espera obtener información acerca de:

- Número de aulas de computación disponibles para alumnos.

- Número de computadoras operativas disponibles para alumnos.

- Características técnicas de las computadoras.

- Número de aulas de computación disponibles.

- Número de computadoras operativas dis- ponibles para docentes.

- Características técnicas de las computadoras.

- Número de reportes de caídas del servidor de la intranet.

- Descripción de cuán intuitiva y amigable es la interfaz.

- Tipos de funcionalidades que ofrece a docentes

- Frecuencia y tipo de uso de los centros de computación en preescolar.

- Frecuencia y tipo de uso de tabletas en primaria.

- Frecuencia y tipo de uso del aula de computación de secundaria.

\section{Conclusiones}

A tenor de los datos recabados en esta primera fase de la investigación y gracias a la aplicación del cuestionario y la revisión documen- 


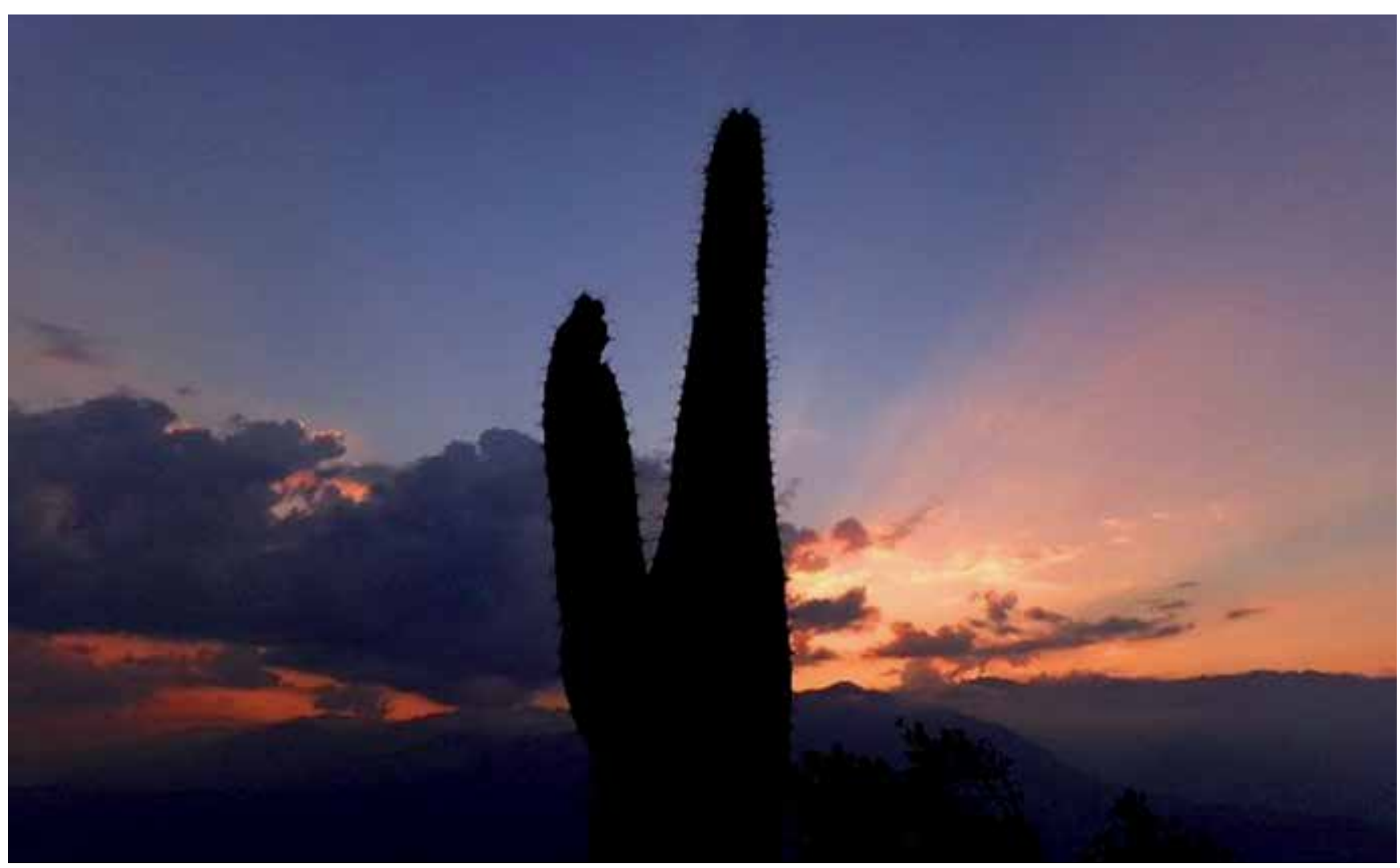

tal se concluye que existe evidencia de cierta integración de las TIC en los procesos de enseñanza-aprendizaje del centro. La mayoría de los docentes usan diariamente su computadora con fines educativos. El uso de los proyectores de vídeo y parlantes como apoyo al docente también es evidenciado.

En relación con la competencia docente en el uso de programas de uso frecuente, también, si bien la mayor parte de la plantilla los domina a nivel básico o medio, una cantidad no menos importante precisa de capacitaciones en el uso de los mismos. En lo que se refiere al manejo de recursos o plataformas educativas online, se encuentra que los profesores se consideran competentes básicos o medio. Llama especialmente la atención que la mitad del profesorado considere indispensable el uso de las TIC en todas las facetas de la enseñanza actual. Por otro lado, la mayoría de los docentes del centro valora como alto su interés por las TIC en la educación.
Es destacable que aunque todavía sea pronto para realizar un diagnóstico completo y profundo de la información obtenida en esta primera fase de investigación, sí se puede extraer que existe cierto nivel de integración de las TIC en los procesos de enseñanza-aprendizaje, al mismo tiempo que se señala la necesidad institucional de proveer a un número considerable de sus docentes con más formación en TIC o incluso con un programa integral de capacitación. También se debe incidir en las necesidades de equipos técnicos que demandan los docentes: proyectores, altavoces y cables HDMI, y también de licencias para plataformas educativas en línea.

Una vez que finalice la investigación se podrá considerar la realización de un nuevo estudio sobre el grado de adquisición de la Competencia Digital por parte del profesorado y el alumnado. Con la información que se obtuviese se podrían identificar las áreas competenciales en las que se debería centrar el coordinador TIC para promover su desarrollo en el centro. 


\section{Referencias}

Álvarez, F., \& Gisbert, M. (2015). Grado de alfabetización informacional del profesorado de secundaria en España: Creencias y autopercepciones. Comunicar: Revista Científica de Comunicación y Educación, 23(45), 187-194.

Álvarez, G. (2012). Entornos virtuales de aprendizaje y didáctica de la lengua: dos experiencias con integración de TIC para mejorar las habilidades de lectura y escritura de estudiantes preuniversitarios (Artículo de investigación académica, científica y tecnológica). Revista $Q$, 6(12), 23. Recuperado de https://dialnet.unirioja.es/servlet/articulo?codigo $=3989798$

Bosco, A. (2005). Las TIC en los procesos de convergencia europea y la innovación en la universidad: oportunidades y limitaciones. Aula abierta, (86), 25. Recuperado de https://dialnet.unirioja.es/descarga/articulo/2328661. pdf

British Educational Communications and Technology Agency. (2004). A Review of the Research Literature on Barriers to the Uptake of ICT by Teachers. London. UK: BECTA. Recuperado de http://dera.ioe.ac.uk/1603/1/becta_2004_ barrierstouptake_litrev.pdf

Cabero, J. (2001). Tecnología educativa. Diseño y utilización de medios en la enseñanza. Barcelona: Ediciones Paidós.

Cabero, J. (2010). Los retos de la integración de las TIC en los procesos educativos. Límites y posibilidades. Perspectiva Educacional, Formación de Profesores, (49), 43. Recuperado de http://www.redalyc.org/articulo. oa?id=333327288002

Carrera, X., y Gisbert, M. (2015). La competencia digital de los docentes. Projecte Interdepartamental de Competència Digital Docent. XVIII Congreso Internacional Edutec.

Carrera, X., Vaquero, E., y Balsells, M. (2011). Instrumento de evaluación de competencias digitales para adolescentes en riesgo social. Edutec: Revista Electrónica de Tecnología Educativa, 35, 1-25.

Casas, L. M., Luengo, R., y Barrantes, G. (2011). Obstáculos percibidos para la integración de las TIC por los profesores de infantil y primaria en Extremadura. Pixel-Bit. Revista de Medios y Educación, 39, 83-94. Recuperado de http://www.redalyc.org/articulo.oa?id=36818685008

Chacón, A. (2009). La tecnología educativa en el marco de la didáctica. En Carrillo, J. A.O., y Medina, A.C. (Coords). Nuevas tecnologías para la educación en la era digital ( $p$. 1). Madrid: Ediciones Pirámide.

Christ, T. (2007). A recursive approach to mixed methods research in a longitudinal study of postsecondary education disability support services. Journal of Mixed Methods Research, 1(3), 226-241.

Claro, M. (2010). Impacto de las TIC en los aprendizajes de los estudiantes: estado del arte. Santiago: Comisión Económica para América Latina y el Caribe.

Condie, R., y Munro, B. (2007), The Impact of ICT in Schools: a landscape review. UK: Becta.

Cutanda, E. (2002). Análisis y evaluación de las plataformas de teleeducación en España. Aplicabilidad al sector educativo de enseñanza secundaria post-obligatoria. (Tesis de doctorado. Directores: Rodenes Adam, M. y Torralba Martínez, J.M.). Valencia: Universidad Politécnica de Valencia.
De Juanas, A., y Fernández, P. (2008). Competencias y estrategias de aprendizaje. Reflexiones sobre el proceso de cambio en el EEES. Cuadernos de Trabajo Social, 21, 217230.

Diario Oficial de la Generalitat de Catalunya. (2016). Resolución ENS/1356/2016, de 23 de mayo, por la que se da publicidad a la definición de la Competencia Digital docente. Departamento de Enseñanza. Recuperado de http:// portaldogc.gencat.cat/utilsEADOP/AppJava/PdfProvide rServlet?versionld $=1500244$ ytype $=01$

Diario Oficial de la Unión Europea. (2006). Recomendación del Parlamento Europeo y del Consejo de 18 de diciembre de 2006 sobre competencias clave para el aprendizaje permanente (p. 6). Bruselas: DOUE. Recuperado de http:// infofpe.cea.es/fpe/norm/Rec\%2018_2006.pdf

Duarte, J., Moreno, M., y Gargiulo, C. (2011). Infraestructura escolar y aprendizajes en la educación básica latinoamericana: Un análisis a partir del SERCE. Washington D.C.: BID Recuperado de http://idbdocs.iadb.org/wsdocs/getdocument.aspx?docnum $=36201660$

Fernández. (2014). A Cañiza artística: experiencia de proxecto interdisciplinar e colaborativo de profesorado e alumnado sobre patrimonio artístico con integración das TIC e participación das familias. Revista Galega do ensino. Recuperado de http://www.edu.xunta.es/eduga/598/ proxeccions/caniza-artistica

Font, J., Hernández, F., Ochoa, M., y Hernández, V. (2007). Integración del diseño asistido y las TIC en la ingeniería gráfica. In Atti del Convegno Nazionale XVI ADM-XIX INGEGRAF. EDIZIONE ETS, p.7-8. Disponible en: http://hdl. handle.net/2117/22415

Harrison, C., Comber, C., Fisher, T., Haw, K., Lewin, C., Lunzer, E., y Watling, R. (2002). ImpaCT2: The impact of information and communication technologies on pupil learning and attainment. British Educational Communications and Technology Agency (BECTA). Recuperado de http:// dera.ioe.ac.uk/id/eprint/1572

Hernández, M. (2012). La integración de las TIC en la clase de ELE. Panorama de una (r)evolución. Revista Internacional de Lenguas Extranjeras = International Journal of Foreign Languages, 1, 63-99. [en línea]. Recuperado de: http:// raco.cat/index.php/RILE/article/view/270169/357751

Hernández, R., Fernández, C., y Baptista, P. (2010). Metodología de la investigación (5a ed.). México: Editorial Mc Graw-Hill.

HMIE. (2005). The Integration of Information and Communications Technologies in Scottish Schools. An interim report by HM Inspectors of Education. Recuperado de http:// www.hmie.gov.uk/documents/publication/EvICT\%20 Final\%2018\%200ct.pdf

Sanmamed, G. (2005). La integración de las tecnologías de la información y la comunicación en la educación superior: experiencias en la UDC. Experiencias y prácticas educativas con nuevas tecnologías (pp. 69-88). AICA Ediciones.

Johnson, L., Adams, S., Estrada, V., y Freeman, A. (2015). NMC horizon report: 2015 K-12 edition. Austin: The New Media Consortium. Recuperado de https://www.nmc.org/publication/nmc-horizon-report-2015-k-12-edition/

Larenas, D., Solar, I., Hernández, S., y Solar, C. (2015). Las percepciones de los profesores respecto a la investigación e 
innovación en sus contextos profesionales. Actualidades Investigativas en Educación, 15(2).

López, S. (2010). Actitudes de los docentes respecto a las TIC, a partir del desarrollo de una práctica reflexiva. $E A$, Escuela Abierta: Revista de Investigación Educativa, (13), 37-54.

Lucena, H., Martín, F., y Díaz, A. (2002). Las actitudes de los docentes hacia la formación en tecnologías de la información y comunicación (TIC) aplicadas a la educación. Contextos Educativos: Revista de Educación, (5), 253-270.

Lugo, T. (2010). Las políticas TIC en la educación de América Latina. Tendencias y experiencias. Revista Fuentes, 10, 52-68. Recuperado de https://idus.us.es/xmlui/handle/11441/32395

Martínez, R., y Urbina, S. (2008). Uso de los recursos tecnológicos en las aulas inteligentes que dan los profesores de la Preparatoria del Tecnológico de Monterrey, Campus Hidalgo. Revista EGE, (14), 12-18.

Mayenco, M. (2009). Uso de las TIC en el aula. Recuperado de http://www.csi-csif.es/andalucia/modules/mod_ense/ revista/pdf/Numero_22/MANUELA_MAYENCO_1.pdf

Morán, L., y Álvarez, G. (2014). Currículum abierto y flexible: análisis del caso de una materia universitaria con integración de TIC. Edutec. Revista Electrónica de Tecnología Educativa, 0(45). Recuperado de http://www.edutec.es/ revista/index.php/edutec-e/article/view/11/pdf_24

Ofelia, P. (2011). Aplicación de plataformas virtuales LCMS en la materia de técnicas de estudio para determinar nuevas metodologías de aprendizaje en educación a distancia. Universidad Central del Ecuador.

Pantoja, A., y Huertas, A. (2010). Integración de las TIC en la asignatura de Tecnología de Educación Secundaria. Pixel-Bit. Revista de Medios y Educación. Recuperado de http://www.sav.us.es/pixelbit/pixelbit/articulos/n37/18. pdf

Passey, D., \& Rogers, C. (2004). The Motivational Effect of ICT on Pupils. UK: Lancaster University. Recuperado de http://www.dfes.gov.uk/research/data/uploadfiles/RR523new.pdf

Poole, B. (1999). Tecnología educativa. Madrid: Mac Graw Hill.

RedXXI Educacyl Digital. (s.f). Herramienta de autoevaluación de la competencia digital. Autoevaluación TIC. Recuperado el 30 de abril de 2016 de https://autoevaluaciontic.educa.jcyl.es/
Ruiz, M., y Sánchez, G. (2014). Rendimiento académico y TIC: una experiencia con webs didácticas en la Universidad de Murcia. Pixel-Bit: Revista de Medios y Educación, 44, 180. Recuperado de http://acdc.sav.us.es/pixelbit/images/stories/p44/12.pdf

Salinas, J. (2000). El rol del profesorado en el mundo digital. En Del Carmen, L. (ed.). Simposio sobre la formación inicial de los profesionales de la educación. Universitat de Girona. Recuperado de www.ffa.sld.cu/uvs0903profesoradoenmundodigital.pdf

Salinas, J. (2016). D + I en mi proyecto de TFM [Mensaje en Foro]. Recuperado de http://moodle.urv.cat/moodle/ $\mathrm{mod} /$ forum/search.php? search=ecl\%C3\%A9ctica\& id $=61663$

Sánchez. (2015). Una experiencia de formación docente para el uso didáctico de las TIC en los procesos de aprendizaje con la implementación de los modelos SAMR y TPCK. Investigar con y para la sociedad (pp. 1911-1918). Recuperado de http://avanza.uca.es/aidipe2015/libro/ volumen3.pdf

Torres, T., Díaz, A., y Reche, C. (2015). Análisis del uso e integración de redes sociales colaborativas en comunidades de aprendizaje de la Universidad de Granada (España) y John Moores de Liverpool (Reino Unido). Revista Complutense de Educación.

Valdés, A., Angulo, J., Urías, M., García, R., y Mortis, V. (2011). Necesidades de capacitación de docentes de educación básica en el uso de las TIC. Pixel-Bit. Revista de Medios y Educación.

Valdez, I. (2011). Encuesta para profesores sobre el uso de las tecnologías de la información y la comunicación, TIC. Universidad Nacional Autónoma de México. Facultad de Ingeniería, División de Ciencias Básicas. Recuperado de http://dcb.fi-c.unam.mx/ProyectoTICS/contenidos/encuestaDCB_TICS-2012-1.pdf

Vera, A., Torres, E., y Martínez, E. (2014). Evaluación de competencias básicas en TIC en docentes de educación superior en México. Píxel-Bit. Revista de Medios y Educación, 44, 143-155. Recuperado de http://acdc.sav.us.es/pixelbit/images/stories/p44/10.pdf

Wenglinsky, H. (1998). Does it compute? The relationship between educational technology and student achievement in mathematics. Educational Testing Services (ETS) Policy Information Report. 